\title{
Isocitrate Dehydrogenase Mutations in Human Cancers: Physiopathologic Mechanisms and Therapeutic Targeting
}

\author{
Elvira Pelosi, Germana Castelli and Ugo Testa*
}

Department of Hematology, Oncology and Molecular Medicine, Viale Regina Elena 299, 00161, Rome, Italy

\begin{abstract}
Isocitrate dehydrogenase (IDH) is a metabolic enzyme responsible for the enzymatic conversion of isocitrate to $\alpha$-ketoglutarate $(\alpha-\mathrm{KG})$. Mutations in the $I D H$ gene result in a novel gain-offunction, with development of neomorphic enzymatic activity determining the pathological reduction of $\alpha$-KG to (R)-2-hydroxyglutarate. The accumulation of this pathological metabolite (onco-metabolite) in cancer cells is, to a large extent, responsible for the development of several cancers, including acute myeloid leukemia (AML), low-grade gliomas (LGGs) or chondrocytic tumors. Furthermore, various experimental studies have shown that $I D H$ mutations represent an early, driver event, conserved during tumor progression in neoplasias such AML and LGG. Given all these observations, potent and selective IDH inhibitors have been developed and are currently under investigation in phase I/II clinical studies. In particular, AG-221, a first-in-class inhibitor of mutant IDH2, was tested in hematological patients with refractory/ relapsing AML or myelodysplasia and showed an overall response rate of 59/159 (37\%), as well as a good safety profile. Similarly, AG-120, an inhibitor of mutant IDH1, was tested in 66 relapsing/ refractory AML patients and showed an overall response rate of $36 \%$, with a complete response rate of $16 \%$. A new IDH inhibitor, AG-811 displayed the capacity to inhibit both mutants IDH1/2 and to penetrate the blood: brain barrier, a property that would be suitable for treatment of glioma patients. On the other hand, additional observations have suggested that IDH-mutant AMLs are sensitive to treatment with BCL-2 inhibitors and to the differentiative induction with all-trans retinoic acid. In conclusion, the collective studies carried out in recent years on the characterization of IDH-mutant tumors highlight an admirable paradigm of the virtuosic transfer from basic research (with improvements in our understanding of the physio-pathological role played by IDH mutations in the development of some tumors) to clinical studies (with the development of selective, potent and clinically-active IDH inhibitors).
\end{abstract}

\footnotetext{
Keywords: Isocitrate dehydrogenase; Cancer; New drugs; Leukemia; Glioma.

Abbreviations: IDH, isocitrate dehydrogenase; AML, acute myeloid leukemia; alpha-KG, alpha-ketoglutarate; 2-HG, 2-Hydroxyglutarate; LGG, low-grade glioma; HGG, high-grade glioma; MDS, myelodysplastic syndrome; AITL, angioimmunoblastic T cell lymphoma; ECC, extrahepatic cholangiocarcinoma; ICC, intrahepatic cholangiocarcinoma.

Received: 16 July 2016; Revised: 01 September 2016; Accepted: 09 September 2016 DOI: $10.14218 /$ JERP.2016.00019

${ }^{*}$ Correspondence to: Ugo Testa, Department of Hematology, Oncology and Molecular Medicine, Istituto Superiore di Sanità, Viale Regina Elena 299, 00161, Rome, Italy. Tel: 0039-649902422, Fax: 0039-649387087, E-mail: ugo.testa@iss.it
}

Introduction

The human genome has five isocitrate dehydrogenase (IDH; EC 1.1.1.42) genes, coding for three distinct IDH enzymes, the activities of which are dependent on either nicotinamide adenine dinucleotide phosphate (NADP; $\mathrm{NADP}^{+}$-dependent IDH1 and IDH2) or nicotinamide adenine dinucleotide $\left(\mathrm{NAD} ; \mathrm{NAD}^{+}\right.$-dependent IDH3). Both IDH2 and IDH3 are localized in the mitochondria and participate in the citric acid cycle for energy production, whereas IDH1 is localized in the cytoplasm and peroxisomes. IDH3 catalyzes the third step of the citric acid cycle, wherein $\mathrm{NAD}^{+}$is converted to NADH in the mitochondria. IDH enzymes catalyze the oxidative decarboxylation of isocitrate to produce $\alpha$-ketoglurate $(\alpha-K G$, also known as 2-oxoglutarate) and concomitantly produce NADPH from $\mathrm{NADP}^{+}$. IDH enzymes also catalyze the reductive carboxylation of $\alpha-\mathrm{KG}$ to form isocitrate and concomitantly produce $\mathrm{NADP}^{+}$from NADPH. IDH is dependent on $\mathrm{NADP}^{+}$and on $\mathrm{Mg}^{2+}$.

The enzymatic reaction catalyzed by IDHs is a two-step process, in which the first step involves oxidation of isocitrate to oxalosuccinate, with the second step involving decarboxylation of the carboxyl group beta to the ketone, ultimately forming $\alpha-\mathrm{KG}$ (Fig. 1). The $\mathrm{Mg}^{2+}$ cofactor is required for the stabilization of the transitional states during the two-step reaction. The IDH1 and IDH2 enzymes are structurally organized as homodimers, while the IDH3 enzyme is organized as a heterodimer, composed by two alpha subunits, one beta subunit and one gamma subunit. The structure of IDH is composed of 14 alpha helices and 18 beta sheets. The alpha helices are located all over the structure, whereas the beta sheets (parallel and anti-parallel) are found mainly through the center of the molecule.

The crystal structure of mammalian IDH1 and IDH2 was determined and showed that each enzyme is composed of a homodimer. ${ }^{1,2}$ Each homodimer is, in turn, composed by a large domain, a clasp domain and a small domain, and contains two asymmetric and identical active sites (composed by a cleft formed by the large domain of a subunit and the small domain of the other IDH homolog). The active sites of the enzyme are accessible to substrate and cofactors; the function of the clasp is to maintain the two subunits together to form the active enzymatic site. Each IDH enzyme possesses: (a) an inactive open conformation, which is maintained through intramolecular interactions between Ser95 and Asp279 residues that serve to block access to the active site; and (b) a catalytically active closed conformation, where the $\mathrm{Mg}^{2+}$-isocitrate complex is able to bind between the large and small domains of the enzyme, consequent to relief of the steric impediment by Asp279 to the $\mathrm{Mg}^{2+}$-isocitrate complex binding. ${ }^{1,2}$

In its active conformation, the enzyme catalyzes $\alpha-\mathrm{KG}$ and NADPH production and then either remains in its active conformation 


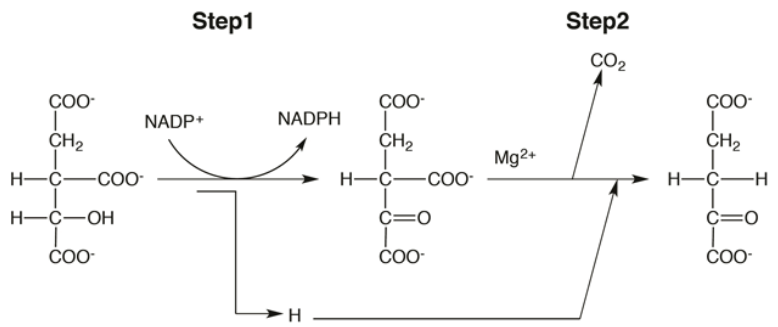

Isocitrate

Oxalosuccinate a-Ketoglutarate
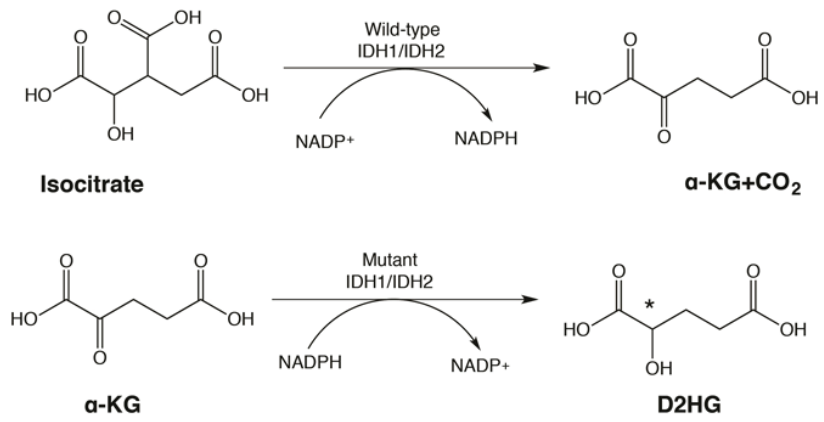

Fig. 1. Enzymatic reactions catalyzed by wild-type and mutant IDH1 and IDH2. (A) Normal IDH1 and IDH2 enzymes catalyze a two-step reaction. In the first step, isocitrate is oxidized to an unstable intermediate (oxalosuccinate), with concomitant reduction of $\mathrm{NADP}^{+}$to NADPH. In the second step, the oxalosuccinate losses its beta-carbonyl group, which is released as $\mathrm{CO}_{2}$, giving rise to the formation of $\alpha-\mathrm{KG}$. The two $\mathrm{H}^{+}$atoms produced during conversion of isocitrate to oxalosuccinate are used for $\mathrm{NADP}^{+}$reduction to NADPH and for conversion of oxalosuccinate to $\alpha-\mathrm{KG}$. (B) Mutant IDH1 and IDH2 enzymes catalyze a reaction wherein $\alpha-\mathrm{KG}$ is reduced to (R)-2-hydroxyglutarate (D-2-HG) with concomitant oxidation of NADPH to NADP ${ }^{+}$ From a structural point of view, $\alpha-\mathrm{KG}$ and $\mathrm{D}-2-\mathrm{HG}$ are very similar and differ only in replacement of the ketone group that is present in $\alpha-\mathrm{KG}$, with the hydroxyl group present in D2HG.

(continuing to catalyze the isocitrate decarboxylation) or returns to its inactive conformation (restoring the Ser94-Asp279 interaction). The main biologic/physiologic function of IDH1/2 is related both to the biosynthesis of essential metabolites in the context of the tricarboxylic acid (TCA) cycle and in providing, together with the pentose phosphate pathway, one of the two essential cellular systems for the generation of NADPH (Fig. 2).

NADPH is required to maintain reduced glutathione pools and to support reductive biosynthesis. Cytosolic NADPH is mainly regenerated via the oxidative pentose phosphate pathway and in the reactions catalyzed by IDH, malate enzyme and aldehyde dehydrogenase and methylene tetrahydrofolate dehydrogenase. Particularly, for that which concerns IDHs, the reductive carboxylation of $\alpha$-KG to isocitrate by IDH2 consumes mitochondrial NADPH, with citrate/isocitrate transported to the cytoplasm where these metabolites can be oxidized by IDH1 to produce cytosolic NADPH (Fig. 2) ${ }^{3}$ The reverse cycle produces mitochondrial NADPH. ${ }^{3}$

In line with these observations, it is not surprising that lower NADPH levels have been reported in IDH1-mutant glioblastoma cells. ${ }^{4}$ The reaction catalyzed by IDH is one of the irreversible reactions in the TCA cycle and, therefore, needs to be carefully regulated. Thus, IDH is allosterically regulated in a positive way by adenosine diphosphate (ADP) and inhibited by adenosine triphosphate (ATP), NADPH or NADH. As such, IDH catalyzes its reaction only when ADP levels are low, while in the presence of high ATP, NADPH or NADH levels, the enzyme is inhibited, because there are existing sufficient amounts of these TCA cycle products that are available for other metabolic cycles.

In addition to TCA, glutamine-glutamate- $\alpha-K G$ metabolism represents an important step in the physiologic effects of IDH and is a critical pathway in IDH-mutant tumors. In this metabolic pathway, glutamine is first lysed to glutamate by the enzyme glutaminase, after which the glutamate is converted to $\alpha$-KG by three different enzymes: glutamate dehydrogenase, alanine transaminase or aspartate transaminase (Fig. 2). Glutaminolysis is active in proliferating and, particularly, in tumor cells, where it represents the crucial source of nitrogen for amino acid synthesis via glutamate production and transamination. Importantly, the hypoxic microenvironment present in tumors stimulates glutamine flux into citrate for production of NADPH by IDH and for lipid production (reviewed in 5). ${ }^{5}$

IDH genes encode the metabolic enzymes $\mathrm{NADP}^{+}$-dependent isocitrate dehydrogenase, involved in the catalyzation of the oxidative decarboxylation of isocitrate to synthesize an $\alpha-K G$. The two distinct IDH1 and IDH2 enzymes show a high degree of sequence similarity (about $70 \%$ ) and are encoded by two distinct genes: $I D H 1$ located on $2 \mathrm{q} 33$, and $I D H 2$ located on $15 \mathrm{q} 26$. These genes are frequently mutated in some tumor types and represent the metabolic genes most frequently mutated in human cancers. It is reported that $I D H 1 / 2$ genes are mutated in $50-80 \%$ of low-grade gliomas and secondary glioblastomas, about $20 \%$ of acute myeloid leukemia (AML), $50-60 \%$ of chondrosarcomas, about $10 \%$ of intra-hepatic cholangiocarcinoma (CCA) and 10\% of melanomas.

The IDH1 and IDH2 enzymes catalyze identical enzymatic reactions, but are localized to different cellular compartments, with the IDH1 enzyme localized in the cytosol and the IDH2 enzyme localized in the mitochondria. The frequency of IDH1 and IDH2 mutations are different in various tumor types; $I D H 1$ and $I D H 2$ mutations are almost equally frequent in AML, while $I D H 1 \mathrm{mu}-$ tations are predominant in gliomas, chondrosarcomas and CCAs. The mutant IDH enzymes have lost the capacity to efficiently carry out the normal oxidative reaction (i.e. conversion of isocitrate and $\mathrm{NADP}^{+}$to $\alpha-\mathrm{KG}, \mathrm{CO}_{2}$ and NADPH), but they have acquired a novel enzymatic function (i.e. conversion of $\alpha-\mathrm{KG}$ to D-2-hydroxyglutarate $(2-\mathrm{HG})$.

In normal tissues, 2-HG is present only at very low levels. In IDH1/2-mutant tumor cells, however, it is markedly accumulated and has been shown to act as a potent oncometabolite, responsible for the induction of many of the epigenetic alterations observed in these tumor cells. ${ }^{6,7}$ The oncogenic effects induced by 2-HG are mainly related to the inhibition of $\alpha-\mathrm{KG}$-dependent dioxygenases activity. The metabolic consequences of IDH1/2 mutations are not completely understood. However, some studies have indicated that overexpression of mutant IDH1 or IDH2 alters the levels of several metabolites, including some amino acids, glutathione metabolites and TCA cycle intermediates. ${ }^{8}$ Other studies have shown an increased sensitivity to glutaminase inhibitors and an inactivation of NADPH-dependent reactive carboxylation due to reduced glutaminase activity. 9,10

Studies of metabolic flux have shown that IDH1 mutations can induce an increase in cellular metabolic flux along the TCA cycle, as well as in respiration, and can compromise the conversion of glutamine to citrate, AcCoA and fatty acids under hypoxic conditions. ${ }^{11}$ Importantly, cells expressing mutant IDH1 are sensitive to pharmacologic inhibition of mitochondrial oxidative metabolism. ${ }^{11}$ Yet, small molecules inhibiting IDH1 enzymatic activity and preventing D-2-HG accumulation fail to rescue abnormal metabolism under hypoxia. ${ }^{11}$ This observation suggests that a doubletargeting strategy may represent an important therapeutic option, based on inhibition of both mutant enzymatic activities by using IDH inhibitors and targeting mutant IDH1-induced metabolic li- 


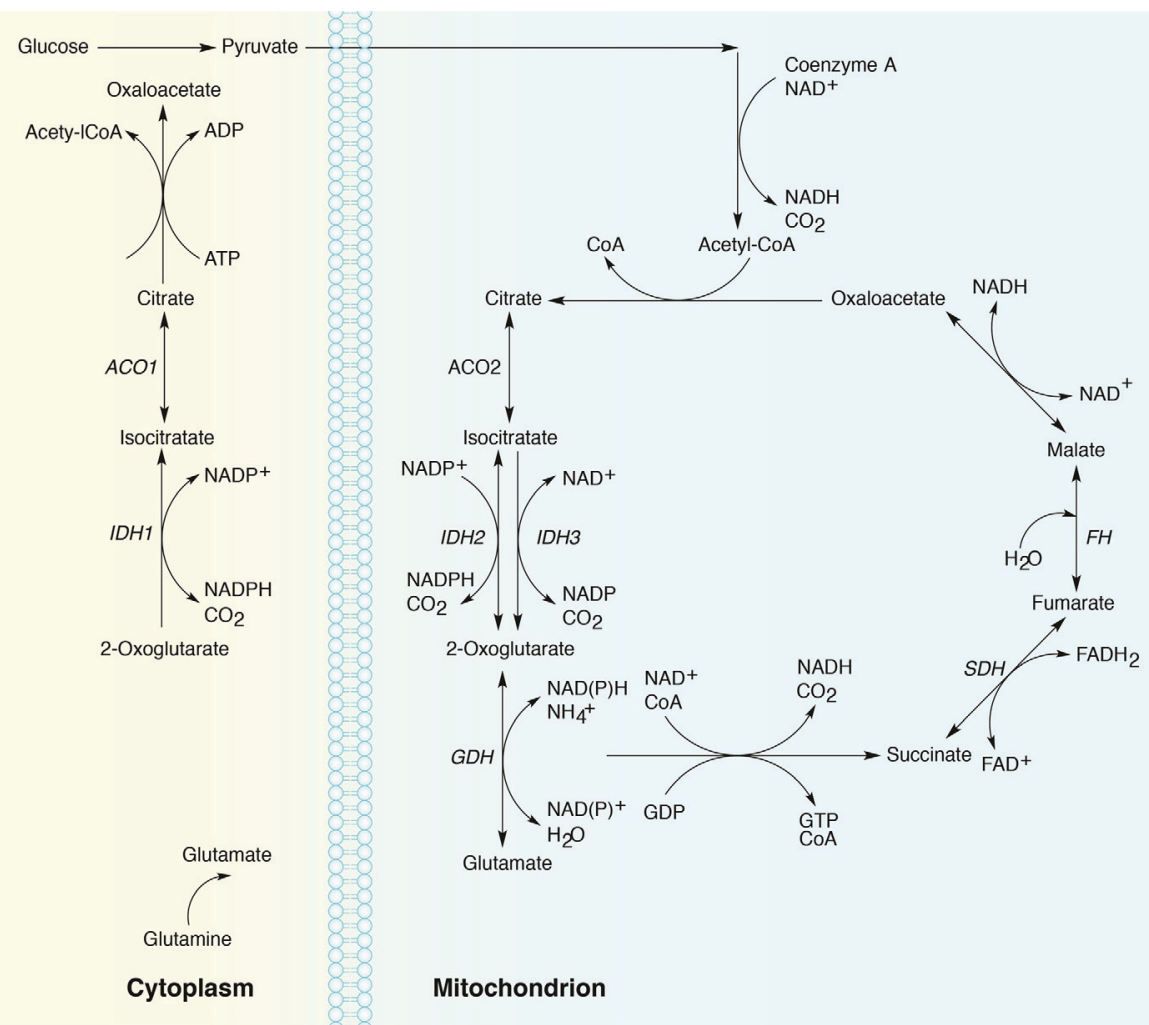

Fig. 2. Function of IDH1/2 and IDH3 enzymes in the context of the tricarboxylic acid (TCA) cycle. In this schematic representation, the mitochondrial reactions involving IDH2 and IDH3 and the cytoplasmic reactions involving IDH1 are shown. IDH1 is located in the cytoplasm and catalyzes the NADP ${ }^{+}$-dependent conversion of isocitrate to $\alpha-\mathrm{KG}$ (also known as 2-oxoglutarate). IDH2 is located in the mitochondria and catalyzes the same reaction. IDH3 is located in the mitochondria and catalyzes the NAD ${ }^{+}$-dependent irreversible transformation of isocitrate to $\alpha-\mathrm{KG}$. The two aconitases (ACO1 and ACO2), glutamate dehydrogenase (GDH), succinate dehydrogenase (SDH) and fumarate hydratase (FH) are also shown.

abilities by drugs such as metformin or phenformin. ${ }^{11}$

In the first section of this review, the main biologic and molecular features of the different types of IDH-mutated tumors are analyzed. In the second section, the development of anticancer therapies targeting mutant IDH enzymes is analyzed, including details of each therapy's actual development and its future perspectives.

\section{Main features of IDH-mutant tumors}

\section{IDH mutations in chondrosarcomas}

IDH1/2 (predominantly IDH1) mutations have been reported in $50-70 \%$ of central chondrosarcomas (Table 1), in about $70 \%$ of conventional chondrosarcomas and $54 \%$ of dedifferentiated chondrosarcomas. These mutations have been found in all tumor grades of the chondrosarcomas, but have not been observed in peripheral chondrosarcomas or in soft tissue tumors. ${ }^{12,13}$ Interestingly, these mutations have also been found in enchondromas, common benign tumors of bone that can be precursors of chondrosarcomas, and very frequently also in enchondromatosis syndromes such as Ollier disease (81\% of $I D H 1 / 2$ mutations) and Maffucci syndrome (77\% of IDH1/2 mutations), associated with DNA hypermethylation. ${ }^{14}$ These patients are at increased risk of developing highlymalignant chondrosarcomas, as well as gliomas and AMLs. These observations have suggested that the acquisition of IDH1/2 mutations is an early event of chondrosarcoma development and may represent a driver event for tumor development. Such a theory is supported by the following two observations: (a) expression of mutant IDH is sufficient to induce benign enchondromas in mouse models, and (b) additional mutations accumulate in chondrosarcomas (such as p16/CDKN2A loss), compared to enchondromas, and, in cooperation with $I D H 1 / 2$ mutations are required for malignant tumor development. ${ }^{15,16}$

In enchondromatosis syndromes, enchondromas progress to chondrosarcomas in up to $30 \%$ of cases. Furthermore, in these syndromes, there is a tendency to develop various types of tumors, including gliomas. Comparison of gliomas developed in enchondromatosis syndromes to those of sporadic IDH-mutated gliomas showed that the former were diagnosed at an earlier age, were more frequently multicentric and were more frequently located within the brainstem than sporadic IDH-mutated gliomas. ${ }^{17}$ At the molecular level, enchondromatosis gliomas were characterized by $I D H$ mutations, but, in contrast to the sporadic IDH-mutated gliomas, do not harbor the 19/19q co-deletion. ${ }^{17}$ IDH1/2 genes were mutated in about $7 \%$ of Ewing sarcoma family tumors. ${ }^{18}$

A recent study provided evidence that mutant IDH1-R132C was able to promote chondrogenic differentiation and to inhibit osteogenic differentiation of normal mesenchymal stem cells. ${ }^{19}$ The frequent presence of mutant IDH in chondrocytic tumors offers a potential therapeutic target, by which enzymatic function can be inhibited with specific small molecule inhibitors. The effect of these inhibitors was tested on chondrosarcoma cell lines and showed an inhibitory effect on cell proliferation, cell survival and cell migration. ${ }^{20}$ 
Pelosi E. et al: Isocitrate Dehydrogenase Mutations in Human Cancers

Table 1. Most frequent IDH1 and IDH2 mutations observed in human cancers

\begin{tabular}{|c|c|c|c|}
\hline Tumor & IDH1 Mutation (\%) & IDH2 Mutation (\%) & Reference \\
\hline Acute myeloid leukemia & $\begin{array}{r}7-9(\text { R132H 50\%) } \\
(\mathrm{R} 132 \mathrm{C} 40 \%) \\
(\mathrm{R} 132 \mathrm{~S} 10 \%)\end{array}$ & $\begin{array}{r}\text { 14-18 (R140Q 60\%) } \\
\text { (R172Q 40\%) }\end{array}$ & $\begin{array}{l}\text { Mardis et al, } 2009 \text { [46]; Marcucci et al, } \\
2010 \text { [49]; Paschka et al, } 2010 \text { [48] }\end{array}$ \\
\hline $\begin{array}{l}\text { Astrocytomas diffuse and } \\
\text { anaplastic (grade II/III) }\end{array}$ & $\begin{aligned} 64-72 & (\mathrm{R} 132 \mathrm{H} \mathrm{90 \% )} \\
& (\mathrm{R} 132 \mathrm{C} \mathrm{5 \% )} \\
& (\mathrm{R} 132 \mathrm{~S} \mathrm{3 \% )} \\
& (\mathrm{R} 132 \mathrm{G} 1 \%)\end{aligned}$ & $\begin{array}{r}1-5(\mathrm{R} 172 \mathrm{~K}) \\
(\mathrm{R} 172 \mathrm{M})\end{array}$ & Wang et al, 1999 [23]; Hartmann et al, 1999 [25] \\
\hline Oligodendroglioma (grade II/III) & $70-82$ & $5-6$ & \\
\hline Oligoastrocytoma (grade II/III) & $66-81$ & $1-6$ & \\
\hline Secondary glioblastoma (grade IV) & 85 & 0 & \\
\hline Primary glioblastoma (grade IV) & $5-8$ & 1 & \\
\hline Chondrosarcoma & $46-52(\mathrm{R} 132)$ & $4-12(\mathrm{R} 172)$ & Amary et al, 2011 [12]; Damato et al, 2012 [13] \\
\hline Myelodysplastic syndromes & $1-2(\mathrm{R} 132)$ & $8-10(\mathrm{R} 140)$ & Patnaik et al, 2012 [78]; DiNardo et al, 2016 [80] \\
\hline Angioimmunoblastic $\mathrm{T}$ lymphomas & 0 & 20 (R172) & $\begin{array}{l}\text { Cairns et al, } 2012 \text { [87]; Odejide et al, } \\
2014 \text { [88]; Wang et al, } 2015 \text { [89] }\end{array}$ \\
\hline Cholangiocarcinoma & $15-25(\mathrm{R} 132)$ & $1-7(\mathrm{R} 172)$ & $\begin{array}{l}\text { Borger et al, } 2012 \text { [90]; Kipp et al, } 2012 \text { [91]; } \\
\text { Wang et al, } 2013 \text { [92]; Goyal et al, } 2015 \text { [93] }\end{array}$ \\
\hline
\end{tabular}

The most frequent amino acid substitutions are indicated and their frequencies at the level of IDH1- or IDH2-mutated patients are reported for acute myeloid leukemias and gliomas.

\section{IDH mutations in bone tumors}

Giant cell tumors (GCTB) are benign but locally-destructive tumors, and include the osteoclast-type multinuclear giant cells. A recent study reported a very high frequency $(80 \%)$ of IDH2-R172S mutations in GCTB. ${ }^{21}$ Furthermore, the IDH2-R172S mutation was reportedly observed in $25 \%$ of osteosarcoma patients..$^{22}$

\section{IDH mutations in gliomas}

Studies carried out over the last 10 years have shown the frequent occurrence of $I D H$ mutations in gliomas. IDH mutations are very frequently $(>80 \%)$ observed in low-grade and secondary glioblastomas, but in $<10 \%$ of primary glioblastomas (Table 1). ${ }^{23,24}$ Particularly, $I D H 1$ mutations were reported to occur in $70-80 \%$ of grade II-III astrocytomas, oligodendrogliomas and oligoastrocytomas, while only a small group (3-5\%) of these tumors were found to display $I D H 2$ mutations, with the $I D H 1 / 2$ mutations being mutually exclusive. ${ }^{23}$ It is, therefore, evident that according to the $I D H$ mutation status, IDH1 mutations have been detected exclusively in low-grade and secondary glioblastomas. In contrast, primary glioblastomas have very low mutation rates for $I D H 1$ or $I D H 2$. Finally, a small percentage of grade II gliomas do not have genetic alterations in $I D H$ or functional mutation in TP53.

Evidence has been provided to support the notion that secondary glioblastomas lacking $\mathrm{IDH} 1$ mutations develop (through a tumor progression process) from an anaplastic glioma (grade III); whereas, the majority of secondary glioblastomas displaying IDH1 mutations appear to develop (through progression) from a World Health Organization (WHO) grade II glioma. ${ }^{25}$ Given this peculiar stratification between primary and secondary glioblastomas, the presence of $I D H$ mutations represent a valuable tool for distinguishing these two conditions. Furthermore, this conclusion is also supported by findings from molecular analyses, showing that primary glioblastomas exhibiting $I D H$ mutations have a mutational profile similar to that typically displayed by secondary glioblas- tomas, thus supporting the hypothesis that primary glioblastomas with $I D H$ mutations originate from pre-existing precursor lesions that were not diagnosed at the time of their occurrence and were therefore misclassified as primary. ${ }^{26}$

Various other studies have shown that IDH mutations are an early event in gliomagenesis, occurring before other genetic abnormalities such as TP53 mutations, loss of $1 \mathrm{p} / 19 \mathrm{q}$, and copy number changes in EGFR and PTEN genes. ${ }^{27,28}$ Mouse model studies using IDH1 mutant xenografts have provided evidence to support that expression of the mutant IDH1 protein is required to sustain glioma cell growth and that pharmacological inhibition of mutant IDH1 with the IDH1-R132H inhibitor results in xenograft growth inhibition. $^{29}$

Importantly, mutations in $I D H 1 / 2$ genes define a subset of human gliomas with a hypermethylation phenotype (G-CIMP), that provide a favorable outcome; in contrast, the absence of $I D H 1 / 2$ mutations identifies a subgroup of low-grade gliomas characterized by poor prognosis. ${ }^{30}$ Although IDH mutant status is associated with better survival, all IDH mutant $/ \mathrm{O}^{6}$-methylguaninemethyltransferase (MGMT) methylation subsets have consistently displayed higher risk of malignant transformation than of death, compared to IDH-wild type (WT) low-grade gliomas. ${ }^{31}$ Recent studies have suggested the classification of gliomas into IDH-WT cases, IDH-mutant group with co-deletion of chromosome arms $1 \mathrm{p}$ and $19 \mathrm{q}$ (IDH mutant-codel) and IDH-mutant group without codeletion (IDH mutant-non-codel). ${ }^{30,32}$ A very recent study based on a very large set of gliomas indicated the existence of three types of IDH-mutated gliomas: (a) the Codel group, consisting of IDHmutant-codel low-grade gliomas; (b) the G-CIMP-low group, including IDH-mutant-non-codel gliomas (both LGGs and glioblastomas) and manifesting a lower degree of DNA methylation; (c) the c-CIMP-high group, including IDH mutant-non-codel gliomas (both LGGs and glioblastomas) and with higher levels of DNA methylation. ${ }^{31}$ The G-CIMP-low group reportedly has a worse survival than the c-CIMP-high and codel groups. ${ }^{33}$

Paired analysis of tumor samples from a large number of glioma patients - comparing higher-grade, progressed samples to their 
lower-grade counterparts - allowed for an integrated genomic characterization of IDH1-mutant glioma malignant progression. ${ }^{34}$ Various oncogenic pathways were shown to drive progression; these included, activation of the MYC and RTK-RAS-PI3K pathways and up-regulation of FOXM1 and E2F2, as well as epigenetic silencing of developmental transcription factors bound by PRC $2 .{ }^{34}$ These findings suggest that IDH mutations are early events in gliomagenesis and cooperate with other more tardive genetic alterations to promote glioma progression. ${ }^{34}$

As stated above, IDH1 mutations have been observed in $<10 \%$ of glioblastomas. Glioblastoma patients with $I D H 1$ mutations are younger and associated with a longer survival than those without IDH1 mutations. ${ }^{19}$ However, in patients with recurrent glioblastomas, the presence of $I D H 1$ mutations is not predictive of progression-free survival (PFS) or radiological response. ${ }^{35}$

In contrast to the IDH-mutant LGGs, the IDH-WT LGGs represent a very heterogeneous group of gliomas, with various imaging and molecular characteristics at the level of genetic abnormalities and expression profiles. ${ }^{36}$ Although these tumors have better PFS and overall survival rates than glioblastomas, their outcomes and clinical presentations are highly variable. ${ }^{36}$ These observations are in line with previous studies showing that some patients with lowgrade gliomas display molecular features of primary glioblastomas, such as EGFR alterations and loss of the CDKN2A locus, both of which are mutually exclusive of $I D H$ mutations. ${ }^{37}$

The oncogenic mechanism of mutant IDH in glioma cells involves production of the onco-metabolite 2-HG, which interferes with iron-dependent hydroxylases pertaining to the TET family. Given the function of TET enzymes, it is not surprising that IDHmutant gliomas manifest a $\mathrm{CpG}$ island methylator phenotype. ${ }^{38}$ Particularly, IDH-mutant gliomas exhibit hypermethylation at cohesion and binding sites of the CTCF; the reduced CTCF binding, in turn, causes deregulated gene expression and, particularly, enhanced PDGFRA expression. ${ }^{26}$ Importantly, treatment of IDHmutant gliomaspheres with demethylating agents, in part, restores CTCF function and reduces PDGFRA expression. ${ }^{38}$ These observations suggest that mutant IDH promotes gliomagenesis allowing aberrant oncogene expression. ${ }^{38}$ When 2-HG levels were elevated in the urine of patients with IDH-mutant and compared with that in patients with IDH-WT glioma, the levels were found to not be affected by the histopathologic grade nor genetic subtype presence of a canonical or noncanonical IDH mutation..$^{39}$ Furthermore, in vitro and in vivo studies have shown that, in human gliomas, the IDH2 mutation leads to greater production of $2-\mathrm{HG}$ than does the IDH1 mutation. ${ }^{40}$

The presence of IDH1/2 mutations in gliomas has a prognostic impact: particularly, glioma patients with IDH-mutant tumors and low/normal Ki67 values have a significantly better prognosis than patients with IDH-WT gliomas showing high Ki67 labeling. ${ }^{41}$ A large portion of IDH-mutant gliomas display ATRX nuclear loss (about $90 \%$ of astrocytomas with ATRX nuclear loss display IDH1/2 mutations and have an astrocytic morphology and a younger age of onset); in contrast, IDH-mutant gliomas with ATRX retention are strongly associated with loss of heterozygosity at $1 \mathrm{p} / 19 \mathrm{q}$ and oligodendroglioma cell morphology. ${ }^{42}$ According to $I D H$ mutation status, $1 \mathrm{p} 19 \mathrm{q}$ codeletion and ATRX-loss grade II gliomas can be subdivided into the following four groups: IDHmut-codel (43\%), IDHmut-codel-ATRX loss (39\%), IDHmutnoncodel-ATRXwt $(6 \%)$, and IDHwt. ${ }^{43}$ The median survival was much better for the IDHmut-codel than for the other three groups. ${ }^{43}$ Moreover, IDH-mutant gliomas are more likely to recur locally and within the radiation field than are IDH-WT tumors, which have a greater tendency toward recurrence distant from the original site of tumor development. Finally, studies carried out in the last few years have shown that grade II and III astrocytomas with $I D H$ mutation have an improved survival, with maximal success rates for surgical resection, and are able to predict response to temozolomide; furthermore, the $I D H$-mutant glioblastomas were shown to display an increased response to concurrent radiotherapy and temozolomide treatment.

The oncogenic mechanism of 2-HG in glioma cells is related not only to DNA hypermethylation but also to additional biochemical mechanisms. Li and colleagues recently showed that R-2-HG induces hypersuccinylation in glioma cells; in fact, this onco-metabolite, through competitive inhibition of the enzyme succinate dehydrogenase, was shown to cause accumulation of the succinylCoA metabolite and hypersuccinylation at the level of mitochondria. ${ }^{44}$ In turn, the hypersuccinylation was responsible for respiration inhibition, mitochondrial depolarization and development of a cancer metabolic phenotype. ${ }^{44}$ The development of mitochondrial dysfunction induced accumulation of BCL-2 anti-apoptotic protein, with consequent resistance of tumor cells to apoptotic stimuli. ${ }^{44}$ The hypersuccinylation contributes to IDH-mediated gliomagenesis, as supported by the experimental evidence showing that relief of the hypersuccinylation condition (either by overexpressing a desuccinylase or by glycine supplementation) reversed BCL2 accumulation and exerted an inhibitory effect on tumor growth. ${ }^{44}$

The possibility of a link between succinylation and IDH2 was also supported by a recent study showing that when the deacetylase Sirtuin 5 (an $\mathrm{NAD}^{+}$-dependent mitochondrial deacetylase) was induced by oxidative stress the desuccinylation of IDH2 was promoted, and, through this mechanism, activated the enzyme, as well as G6PD by deacetylation, thereby maintaining NADPH levels and redox balance to protect the cells against oxidative damage. ${ }^{45}$

\section{IDH mutations in myeloid neoplasia}

\section{IDH mutations in AML}

AML is a heterogeneous hematologic malignancy, characterized by the accumulation of various somatic genetic abnormalities and of immature myeloid cells arrested at various stages of maturation. Studies carried out in the last 2 decades have led to the identification of two broad types of genetic mutations, which cooperate to support development of the leukemic process. The class I mutations confer a survival/growth advantage to hematopoietic stem cells (HSCs) and progenitor cells (HPCs), such as the mutations in $N R A S$ or $K R A S$, the loss of NF1 or the mutations in FLT3 receptor tyrosine kinase. The class II mutations promote self-renewal and block the differentiation of HPCs, such as the $\mathrm{t}(8: 21)$ fusion involving $A M L 1-E T O$ or the $\mathrm{t}(15 ; 17)$ fusion involving $P M L-R A R \alpha$.

In 2009, Mardis and colleagues reported frequent occurrence of IDH1/2 gene mutations occurring in AMLs, a finding that was later confirmed by the Genome Atlas Research Network. ${ }^{46,47}$ These studies and others have provided evidence that $I D H 1 / 2$ mutations occur in about $20 \%$ of AML patients, including 6-16\% IDHI mutations and $8-19 \%$ IDH2 mutations (Table 1). Many studies have reported the main features of IDH-mutated AMLs, providing evidence that these AMLs are characterized by a preferential occurrence in older patients, a preferential normal cytogenetic profile or other intermediate-risk cytogenetics, an increased percentage of leukemic blasts in the bone marrow and peripheral blood at diagnosis, a more frequent association with NPM1 and FLT3 mutations, a frequent association with $D N M T 3 A$ mutation, and mutual exclusivity with $T E T 2$ and $W T 1$ mutations. ${ }^{48-51}$ 
It is important to note that $I D H 1 / 2$ mutations, together with DNMT3A and TET2 gene mutations, contribute to an overall occurrence in AMLs of $>40 \%$ of the mutations in genes involved in the regulation of methylation of genomic DNA. ${ }^{52}$ Analyses of the prognostic impact of $I D H$ mutations in AMLs emerged as a matter of great controversy, with contrasting evidence either supporting a positive, a negative or a neutral impact on AML prognosis (reviewed in 40). ${ }^{40}$ However, a recent study based on a large set of AML patients provided clear evidence that overall survival for IDH-WT AMLs and IDH-mutated AMLs is comparable..$^{53}$

The large majority of leukemia-associated $I D H 1$ and $I D H 2$ mutations occur at the level of arginine residues present in the catalytic pocket of the enzyme, with the IDH1 mutations occurring mostly at arginine 132 (R132H or R132C or R132L or R132S or $\mathrm{R} 132 \mathrm{G}$ ) and those of IDH2 occurring mostly at arginine 172 or 140. These mutations confer to the mutant IDH1 or IDH2 protein a novel oncogenic enzymatic activity that is related to their capacity for allowing production of the R(-) enantiomer of the metabolite R-2-HG, which accumulates in IDH-mutant AMLs. ${ }^{54}$ It was suggested that R-2-HG could represent the oncogenic mediator of IDH mutants in the leukemogenetic process. $\alpha-K G$ is a cofactor of many of the deoxygenases involved in the regulation of various key biologic processes, including nucleic acid repair, hypoxic response, chromatin modification and fatty acid metabolism, while 2-HG acts as an inhibitor of these deoxygenases. ${ }^{55,56}$ According to these findings, however, the leukemogenetic role of R-2-HG remains unclear. ${ }^{57}$

It also remains to be demonstrated whether onco-metabolites such as R-2-HG play a causative role in leukemogenesis or, rather, are only simple biomarkers of oncogenic IDH mutants. However, a recent study using two mouse leukemic models and a patientderived AML xenotransplantation model showed that R-2-HG, but not $\alpha-\mathrm{KG}$, is an onco-metabolite capable of inducing hyperleukocytosis and accelerating the onset of murine and human leukemias in vivo. ${ }^{54}$ Other studies have provided evidence to strongly support the role of serum 2-HG levels at diagnosis as a biomarker of IDH1/2-mutant AMLs; furthermore, the prognostic value of 2-HG levels post-induction have been shown in IDH1/2-mutant patients. ${ }^{58,59}$ Finally, a recent study carried out in $84 \mathrm{IDH}-$ mutant AML patients showed that D-2-HG serum levels in IDH1-mutant, but not in IDH2-mutant, patients have a prognostic impact on outcome; this difference could be tentatively related to the different subcellular localizations of IDH1 and IDH2 enzymes. ${ }^{60}$

An increasing number of studies have provided evidence that IDH mutants exert their pro-oncogenic effect by interfering with the differentiation program of hematopoietic cells. Thus, in 2000 , Figueroa and colleagues analyzed the effects on stable expression of either an IDH1 or IDH2 mutant allele on hematopoietic cell differentiation in the $32 \mathrm{D}$ cultured mouse cells or in primary mouse bone marrow cells; in both of these cellular systems, the expression of an IDH-mutant enzyme induced an increase in stem cell markers and impaired myeloid cell differentiation. ${ }^{61}$ Sasaki and colleagues reported the characterization of a conditional knock-in mouse model, in which the IDH1-R132H mutation was inserted into the murine IDHI locus and expressed in all hematopoietic cells or specifically in cells of the myeloid lineage. ${ }^{62}$ These mutant mice displayed an increased number of early hematopoietic progenitors, impaired myeloid cell differentiation, anemia, splenomegaly and extramedullary hematopoiesis. ${ }^{62}$ The hematopoietic cells of these animals displayed hypermethylated histones and changes to DNA methylation that were similar to those observed in IDH-mutant AMLs. ${ }^{62} \mathrm{~A}$ third set of experiments provided evidence that enforced expression of an IDH-mutant enzyme in or exogenous administration of a soluble form of R-2-HG to the TF-1 human erythroleukemic cells promoted cytokine independence and blocked cell differentiation. ${ }^{63}$

Recent studies have helped to better define how IDH-mutant alleles affect hematopoietic cell differentiation in human leukemic cells. Particularly, several studies have shown that IDH-mutants affect the expression of some genes involved in retinol metabolism and/or signaling. Interestingly, for the four cancers in which $I D H$ mutations are frequently observed, the RAR activation pathway is targeted by IDH-mutants, as shown by two lines of evidence. In the first, RBP1, a downstream target of RAR, was recently shown to become hypermethylated following expression of mutant- $I D H 1$ gene in cell lines, and hypermethylation of the RBPl gene promoter was shown to be associated with down-regulation of RBP1 expression in tumor cells. ${ }^{64,65}$ In the second, the RAR activation pathway was found to be affected in all tumor types associated with frequent IDH mutations (i.e. AML, LGG, chondrosarcoma and CCA), and the process was shown to involve two genes in AML, 17 genes in LGG, 14 genes in chondrosarcoma and 5 genes in CCA. ${ }^{66}$

A recent study by Boutzen and colleagues provided fundamental data towards understanding how IDH-mutants affect the differentiation program of hematopoietic cells. ${ }^{67}$ In fact, gene expression studies carried out on leukemic cells bearing mutant IDH enzymes have clearly shown that IDH1-R132H mutation primes leukemic blasts to granulo-monocytic differentiation (as directly supported by the finding of an enrichment of key transcriptional factors regulating myelopoeisis, such as CEBP $\alpha$, PU.1, RUNX1, CEBP $\beta$, CEBPE). ${ }^{67}$ Particularly, analysis at the level of the CEBP $\alpha$ gene showed that IDH1-mutant AML cells have an increased occupancy of the promoter of this gene by $\mathrm{H} 3 \mathrm{~K} 4 \mathrm{me} 3$, which is associated with expression of $C E B P \alpha$ and of its target genes. ${ }^{67}$ Furthermore, the gene expression analysis also showed that the $I D H 1-R 132 H$ gene signature is particularly enriched in genes that are responsive to treatment with retinoic acid receptor (RAR) ligands, such as all-trans retinoic acid (ATRA). ${ }^{67}$ Importantly, in vitro treatment of IDH-mutant AML cells with ATRA resulted in induction of granulocytic differentiation, associated with a reduction in cell viability that occurred through induction of apoptosis. ${ }^{67}$ In vivo ATRA treatment of immunodeficient mice grafted with human IDH-mutant AML cells resulted in a clear reduction of tumor burden. ${ }^{67}$ Therefore, these observations were of fundamental importance, not only for their implications at the basic research level that improved the overall understanding of the mechanism underlying the perturbation of hematopoietic cell differentiation that is elicited by IDH mutants, but also because they open new perspectives in the treatment of these leukemias. ${ }^{67}$

The inhibitory effect of mutant IDH enzymes on hematopoietic cell differentiation is also directly supported by the observation that AGI-6780, a potent IDH2-mutant inhibitor induces the granulo-monocytic differentiation of IDH2-mutant primary AML blasts in vitro. ${ }^{66}$ These observations, to some extent, are reminiscent of the effect of ATRA on acute promyelocytic leukemia cells, demonstrating that the inhibition of mutant IDH2 can relieve a blockade in differentiation that is present in this leukemia subset. ${ }^{68}$

Other studies have suggested that IDH mutation can act through an inhibition of TET2 effects on DNA methylation. In fact, Figueroa et al showed that $I D H 1 / 2$ mutations are mutually exclusive from TET2 mutations and inhibited the DNA demethylation activity of TET2; furthermore, IDH-mutant and TET2-mutant AMLs displayed overlapping hypermethylation signatures. ${ }^{61}$ However, remarkable differences exist between IDH1- and TET2-mutantinduced myeloid leukemias. In contrast to TET2-knockout mice, transgenic mice expressing mutant $I D H 1$ showed reduced numbers of HSCs; this effect could be related to a down-regulation of 


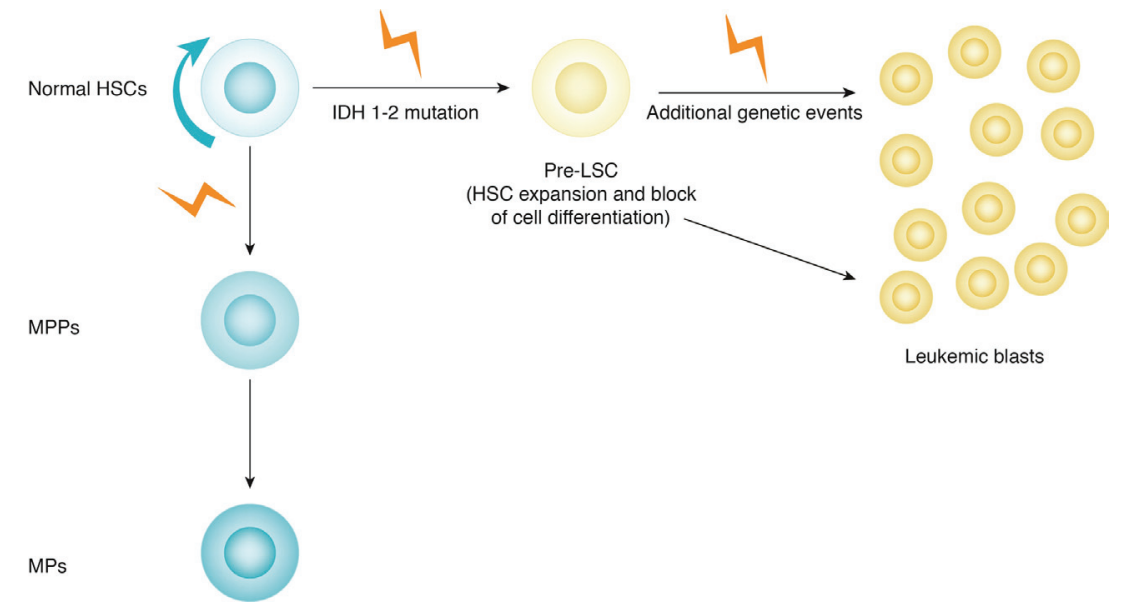

Fig. 3. Schematic model for the acquisition of IDH1/2 mutations during leukemic development. The acquisition of mutations of IDH1/2 (or in other landscaping genes affecting DNA methylation or chromatin modification) at the level of normal HSCs determines the expansion of these cells and a blockade of their differentiation, with the development of the co-called pre-leukemic stem cells (Pre-LSCs). The occurrence of additional mutational genetic events (such as FLT3 mutations) in these cells determines the formation of a fully-active leukemic process.

the DNA damage sensor ATM by alteration of histone methylation, with consequent impaired DNA repair, increased sensitivity to DNA damage and reduced self-renewal of HSCs, independent of TET2. ${ }^{69}$

Development of animal models has been of fundamental importance to the collective efforts of researchers to define the leukemogenetic role of mutant IDH enzymes. Basically, the retroviral transduction of IDH mutations, in combination with additional oncogenes, into primary bone marrow mouse cells and followed by transplantation has been shown to drive leukemia development. ${ }^{70,71}$ Other studies have provided an answer to the fundamental question of whether or not IDH1/2-mutants are required for leukemia maintenance in vivo. To answer this question, Kats and colleagues developed a mouse transgenic model of IDH2-R140Q mutation that has the capacity to be both tissue-specific and on/ off inducible; using this genetic model, it was demonstrated that expression of the transgene elicited an on/off inducible 2-HG production that was comparable to that observed in AML patients. ${ }^{71}$ Expression of mutant IDH2 resulted in alterations within the hematopoietic compartment, characterized by expression of HSCs and a partial blockade of hematopoietic cell differentiation. ${ }^{72}$

Development of compound transgenic models, in which the expression of mutant IDH2 was combined with Meis1 and Hox A9, led to the development of leukemic cells that were dependent on expression/function of mutant IDH for their growth/survival; on the other hand, compound transgenic IDH2-R140Q; Flt3 ${ }^{\text {ITD }}$ mice showed that mutant IDH cooperates with FLT3 ${ }^{\text {ITD }}$ in leukemia inhibition in vivo. ${ }^{72}$ Ogawara and colleagues developed a peculiar model of IDH-dependent leukemia, in which mice were transplanted with $\mathrm{NPM}^{+/-}$hematopoietic stem/progenitor cells co-transduced with four mutant genes (NPMc, IDH2-R140Q, DNMT3A-R882H, and FLT3 $\left.{ }^{\mathrm{ITD}}\right){ }^{73}$ The resultant leukemias that developed in these animals were dependent upon the expression of mutant IDH, as supported by the observation that conditional deletion of IDH2-R140Q blocked 2-HG production and maintenance of leukemic stem cells, resulting in survival of the AML mice. ${ }^{73}$ These observations strongly support the idea of therapeutic targeting of IDH in IDH1/2-mutant AMLs.

Studies carried out in the last few years have provided evidence that the development of a clinically-relevant leukemic disease implies a process of clonal evolution, starting from pre-leukemic clones that contain only some of the genetic alterations observed at the level of leukemic cells (Fig. 3). Importantly, pre-leukemic early genetic alterations would be present in all leukemic cells, whereas mutations present in leukemic subclones would represent mutations acquired at a later time during the leukemic development (Fig. 3)..$^{74}$ Therefore, leukemic therapies aiming to eradicate leukemic cells must target markers/events/genetic abnormalities present in all leukemic cells and, thus, which had developed as early events. The findings from parallel sequencing studies of selected AML patients have provided support for the view that IDH mutations represent an early event during leukemia development. ${ }^{75}$ It is of interest to note that pre-leukemic stem cells preferentially display mutations in "landscaping" genes that are involved in DNA methylation and chromatin modification, such as IDH1, $I D H 2, I K 2 F 1$, and DNMT3A. ${ }^{76,77}$

\section{IDH mutations in myelodysplastic syndromes (MDSs)}

IDH mutations are relatively frequent in MDSs. Patnaik and colleagues reported $I D H 1 / 2$ mutations in $12 \%$ of patients with MDSs, with the $I D H 2$ mutations being much more frequent than the $I D H 1$ mutations. ${ }^{78}$ Mutational frequency was reported as $4 \%$ in patients with refractory anemia with ring sideroblasts, $12 \%$ in patients with refractory cytopenia with multilineage dysplasia, $14 \%$ in patients with refractory anemia with excess blasts (RAEB) type 1 and 23\% in patients with RAEB type $2 .^{74}$ Two other studies reported frequencies of IDH1/2 mutations in MDS in the order of 5-6\%. ${ }^{79,80}$ In one of these two studies, the occurrence of IDH mutations in the MDS patients was found to be associated with older age, higher platelet counts and mutations in DNMT3A, ASXL1 and SRSF2; moreover, in the studied patients, the presence of $I D H 2$ mutations was associated with a poor prognosis (reduced survival). ${ }^{79}$ In the second study, it was shown that IDH1/2 mutations occurred more frequently in patients with diploid and other intermediate-risk cytogenetics and RAEB classification by WHO, and were less frequent in patients with TP53, RUNX1, ASXL1 or TET2 mutations. ${ }^{80}$ Finally, it was reported that, at the time of leukemic transformation, $11.2 \%$ of MDS patients present with an $I D H 1 / 2$ mutation. ${ }^{78}$

Lin and colleagues explored the occurrence of Tet 2 and $I D-1 / 2$ mutations in MDSs at diagnosis and at the time of leukemic trans- 
formation, and reached the conclusion that these mutations were maintained during disease progression. ${ }^{81}$ Moreover, the Tet2, but not the $I D H 1 / 2$, mutations were found to affect the time of progression to leukemic transformation. ${ }^{81}$

\section{IDH mutations in myeloproliferative neoplasms}

IDH mutations have been intensively explored in myeloproliferative neoplasms (MPNs). In an initial study carried out on a very large population of MPN patients, a low incidence of $I D H 1 / 2$ mutations (about $2 \%$ ) was observed during the chronic phase. ${ }^{80}$ Among the various MPNs, the highest incidence of $I D H 1 / 2$ mutations was observed in myelofibrosis (PMF; 4\%), while this incidence was low in polycythemia vera $(2 \%)$ and in essential thrombocytopenia $(0.8 \%){ }^{82}$ Subsequent studies have confirmed that IDH mutations in primary myelofibrosis are predictive of leukemic transformation and shortened survival. ${ }^{83,84}$ Bleeding complications and rate of death were significantly higher in IDH-mutated PMF patients, compared to IDH-WT patients. ${ }^{85}$

It is important to note that, while IDH $1 / 2$ mutations are thought to represent early driver events in leukemogenesis (with stability over time), these mutations are acquired at the time of leukemic transformation in some patients with MPNs.

\section{IDH1/2 mutations in T cell lymphomas}

In 2012, Cairns and colleagues reported for the first time the frequent occurrence (about 20\%) of IDH2 mutations in angioimmunoblastic T cell lymphomas (AITLs) (Table 1). ${ }^{86}$ In the majority of these patients, the IDH2 mutation represented the R172 subtype, and, much more rarely, the R140 subtype. ${ }^{86}$ Interestingly, other T cell lymphomas, such as peripheral $\mathrm{T}$ cell lymphomas, anaplastic large cell lymphoma, enteropathy type $\mathrm{T}$ cell lymphoma, cutaneous $\mathrm{T}$ cell lymphoma, hepatosplenic $\mathrm{T}$ cell lymphoma and extranodal NK/T-cell lymphoma, showed negativity for $I D H$ mutations. ${ }^{86}$ Similarly, no IDH mutations were detected in Hodgkin's lymphoma and non-Hodgkin's B cell lymphoma. ${ }^{86}$

The above findings were confirmed in more recent studies on genetic abnormalities of AITLs and the association of IDH2 mutations with other recurrent mutations was clearly defined. Thus, Sakata-Yanagimoto performed a detailed analysis of genetic alterations occurring in AITLs and showed that three genetic mutations are frequent and occur at the level of RHOA, TET2 and $D N M T 3 A$, in addition to $I D H 2$, and that IDH2-mutated AITLs were constantly associated with RHOA and TET2 mutations (while there was no association found between IDH2 and DNMT3A mutations) ${ }^{87}$ Odejide and colleagues basically confirmed these findings showing that, in the majority of AITL patients, IDH2 mutations co-occurred with TET2 mutations. ${ }^{88}$ Therefore, the co-occurrence of IDH2 and TET2 mutations observed in AITLs sharply contrasts with the mutually exclusive nature of TET 2 and IDH1/2 alterations observed in AMLs.

IDH2R 172 mutations define a subset of patients with AITL characterized by hypermethylation of genes involved in $\mathrm{T}$ cell receptor signaling and $\mathrm{T}$ cell differentiation, with consequent down-regulation of genes associated with $\mathrm{T}_{\mathrm{H} 1}$ differentiation that contributes to lymphomagenesis in this disease. ${ }^{89}$ IDH2R172 mutations have been observed in about $33 \%$ of AITL patients, with $68 \%$ of those patients reportedly also displaying TET2 mutations and about $40 \%$ also displaying DNMT3A or RHOA mutations. ${ }^{89}$ Interestingly, TET2 mutations are very frequent (about $80 \%$ ) in AITL, and the group of TET2-mut/IDH2-WT patients did not show the gene expression signature observed in IDH-mutated AITLs. ${ }^{89}$ Ectopic expression of $\mathrm{IDH} 2^{\mathrm{R} 172 \mathrm{~K}}$ in $\mathrm{CD} 4^{+} \mathrm{T}$ cells was shown to lead to markedly increased levels of $2-\mathrm{HG}$, histone-3 lysine methylation and 5 '-methycytosine, and decreased 5'-hydroxymethylcytosine. ${ }^{89}$

\section{IDH1/2 mutations in CCA}

CCAs comprise malignancies arising from the intrahepatic (ICC), perihilar and distal biliary tree (ECC). The ICC type is the second most common primary hepatic malignancy, after hepatocellular carcinoma, and accounts for $10-20 \%$ of primary liver cancers. Studies carried out in the last few years have shown that IDH mutations are frequent in CCAs. Particularly, IDH mutations have been observed in $16-36 \%$ of ICCs and much more rarely $(0-7 \%)$ in ECCs, and may be associated with clear cell or scarcely differentiated histology (Table 1). ${ }^{90-93} \mathrm{~A}$ recent whole genome sequencing analysis provided evidence that the frequencies of $I D H$ mutations, as well as of KRAS mutants, are clearly higher among ICC patient who are hepatitis-negative. ${ }^{94}$

The prognostic significance of $I D H$ mutations in CCA remains unclear. A study of 326 patients with resected ICC conducted by Wand et al showed that IDH mutations were associated with a better prognosis (longer survival). ${ }^{92}$ Moreover, the IDH-mutated patients in that study showed enhanced p53 expression and DNA hypermethylation. ${ }^{92}$ In contrast, another study carried out in 104 patients with advanced ICCs, no correlation was found between IDH mutations and disease outcome. ${ }^{93}$ Finally, Hayoshi and colleagues provided evidence that IDH mutations in ICC are selectively associated with a clinicopathologic subtype (type II) characterized by low mucin production and positivity for $\mathrm{N}$-cadherin and NCAM. ${ }^{95}$

Interestingly, a recent study showed that IDH blocks liver progenitors from undergoing hepatocyte differentiation via promoted production of $2-\mathrm{HG}$ and suppression of $\mathrm{HNF}-4 \alpha$, a master transcription factor that regulates hepatocyte identity. ${ }^{96}$ In line with this observation, the study also examined genetically engineered mice expressing mutant IDH in the adult liver and found an aberrant response to hepatic injury, which was characterized by HNF$4 \alpha$ silencing, blocked hepatocyte differentiation and remarkably increased levels of liver cell proliferation. ${ }^{96}$ Furthermore, $I D H$ and KRas mutations, genetic alterations co-existing in a subset of ICC patients, were shown to cooperate to drive the expansion of liver progenitor cells and their malignant transformation. ${ }^{96}$

It is important to note that, clinically, ICC shows an aggressive behavior, with poor prognosis, and no standard treatment is available other than surgical resection. Therefore, the identification of therapeutic targets for ICC is of fundamental importance. In this context, the results of a recent study by Saha and colleagues are particularly interesting; the authors reported the identification of a peculiar sensitivity of IDH-mutated tumors to the multikinase inhibitor Dasatinib, displaying a marked induction of apoptosis in ICC cancer cell lines upon treatment. ${ }^{97}$ Molecular studies have identified SRC as a critical Dasatinib target in the IDH-mutant ICC, thus suggesting that these tumor cells have a unique dependency on SRC. 97

\section{IDH inhibitors}

Many molecules capable of targeting mutant IDH1/2 enzymes have been reported in the recent years. Some of these have been investigated in various in vitro and in vivo preclinical models, and 


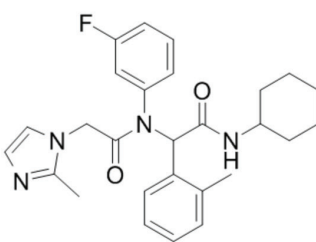

AGI-5198

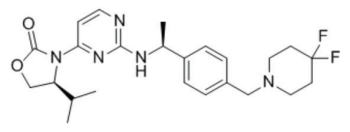

Mutant IDH1-IN-2

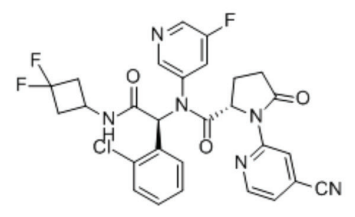

AG-120

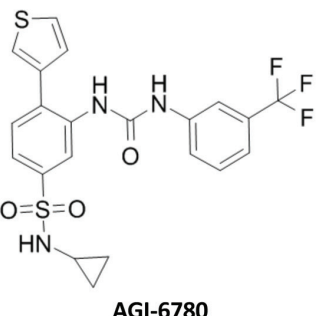

AGI-6780

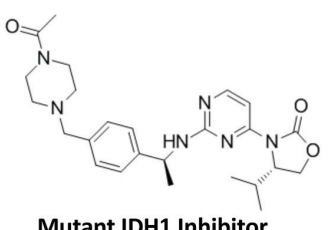

Mutant IDH1 Inhibitor

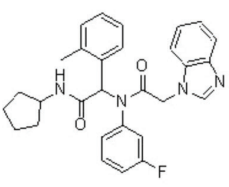

ML309

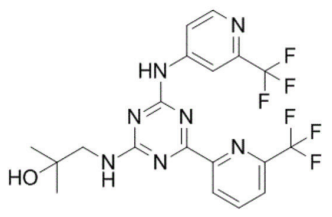

Enasidenib (AG-221)

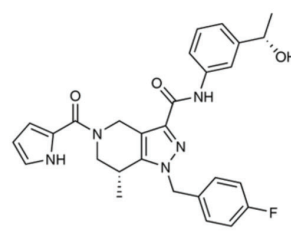

GSK321

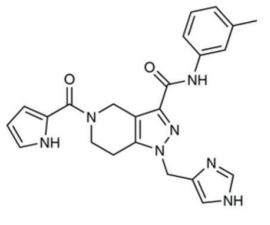

GSK990

Fig. 4. Chemical structures of IDH inhibitors. All the reported molecules are active inhibitors, with the exception of GSK990, a structurally inactive inhibitor.

a few are currently under evaluation in phase I/II clinical studies focusing on the different neoplastic pathologies in which the IDH1/2 enzymes are mutated (Fig. 4). A high-throughput screening allowed the identification of a first series of potent inhibitors of IDH1-mutants; this series consists of a phenyl-glycine scaffold with one stereocenter. ${ }^{98}$ In these compounds, one enantiomer was found to be predominantly responsible for the activity of the racemic mixture. These inhibitors were characterized for their selective inhibitory activity against mutant IDH1 compared to IDH1-WT and for their capacity to markedly reduce $2-\mathrm{HG}$ levels in the U87 MG glioma cell line. ${ }^{98}$ Some of these compounds were investigated only at the experimental level; for example, AGI-5198, an IDH1-mutant inhibitor, which was investigated for its properties to inhibit IDH1-mutant glioma by reducing 2-HG levels and inducing cell differentiation, or HMS-101, an IDH1-mutant inhibitor capable of inducing the apoptosis of primary IDH1-mutant AMLs and of reducing 2-HG levels. ${ }^{21,54}$ Another member of the phenylglycine series is ML309, an IDH1-mutant inhibitor, selective for mutant IDH1 and sparing IDH1-WT (Fig. 4). This inhibitor binds competitively to mutant IDH1 and acts as a reversible inhibitor in competition with $\alpha-\mathrm{KG}$, and not in competition with NADPH. ${ }^{99}$ The compound inhibits 2-HG production in glioma cells, with an $\mathrm{IC}_{50}=250 \mathrm{nM}$, and had displayed minimal in vivo toxicity. ${ }^{99}$

A number of studies have investigated the structural and mechanistic aspects of IDH inhibition by the various IDH inhibitors. Kinetic and structural studies have suggested that the inhibitors could be divided into two categories: (a) those able to bind to the $\alpha-\mathrm{KG} /$ isocitrate site and then act as binding competitors; (b) those able to bind allosterically to the interface between the two promoters of the IDH enzyme molecule dimer. It is evident that the mechanism of enzyme inhibition by the two different types of molecules is completely different. The first ones act as substrate competitors for the binding site, and the second ones, such as AGI-6780, freeze
IDH enzymes in an open pre-catalytic conformation, similar to that which is observed in the absence of $\alpha-\mathrm{KG}$ or isocitrate and is markedly different from the closed conformation observed when the binding site is occupied by $\alpha-K G$ or isocitrate. Two recent studies have more precisely defined the fine molecular mechanisms through which IDH inhibitors determine the blockade of IDHmutant enzyme activity. ${ }^{100,101}$ Deng and colleagues reported that a new selective IDH1 inhibitor acts through interaction with a $\mathrm{Mg}^{2+}$ binding residue that is located at the dimer interface. According to these findings, it was suggested that differences in $\mathrm{Mg}^{2+}$ binding between WT and mutant enzymes may contribute to the selectivity of inhibitors. ${ }^{100}$ In the other study, the crystallographic analysis of the structure of another inhibitor (GSK321) bound to mutant IDH1 showed that the inhibitor binds to an allosteric site and freezes the enzyme into an open, catalytically inactive conformation. ${ }^{100}$ At variance with the other inhibitor, two molecules of the inhibitor GSK 321 bind per enzyme dimer, and this binding was shown to be competitive with $\alpha-K_{G}{ }^{101}$ The biologic effect of this inhibitor on primary IDH1-mutant AML blasts was also tested, and showed an initial increase in viable cells, followed by a late reduction in cell viability coupled with an increase in apoptosis, as well as progressive induction of granulocytic differentiation of leukemic cells, as shown by cell morphology and membrane antigen expression. Study of mice xenotransplanted with IDH1-mutant AML cells revealed a decrease in the stem-like leukemic cells and a reduction in the AML blasts in vivo. Finally, as compared to untreated cells, the treated cells showed overall DNA hypomethylation, with consequent up-regulation of genes associated with progenitor growth and differentiation, such as CD38 and MPO. ${ }^{101}$

Some IDH inhibitors have entered a program of drug development and have already completed testing in phase I clinical trials. The majority of these compounds were developed by the Agios Pharmaceuticals, a publicly-traded American pharmaceutical com- 
Pelosi E. et al: Isocitrate Dehydrogenase Mutations in Human Cancers

Table 2. IDH inhibitors at various stages of clinical development

\begin{tabular}{|c|c|c|c|}
\hline Inhibitor & Specificity & Dosing in $\mathrm{mg}$ & Clinical Studies \\
\hline AG-120 & IDH1 & $\begin{array}{l}100-500(\mathrm{BID}) \\
500-1200(\mathrm{QD}) \\
500 \text { for phase II studies }\end{array}$ & $\begin{array}{l}\text { NCT02074839 Patients with advanced hematologic malignancies and IDH1 } \\
\text { mutations (phase I) } \\
\text { NCT02073994 Patients with advanced solid tumors and IDH1 mutations (phase I) } \\
\text { NCT02632708 Safety of AG-120 or AG-221 in combination with induction and } \\
\text { consolidation therapies in patients with newly diagnosed acute myeloid leukemia } \\
\text { and IDH1 or IDH2 mutations } \\
\text { NCT02677922 Safety and efficacy of AG-120+azacitidine or AG-221+azacitidine } \\
\text { in patients with newly diagnosed acute myeloid leukemia and IDH1 or IDH2 } \\
\text { mutations (phase I/II) }\end{array}$ \\
\hline AG-221 & IDH2 & $\begin{array}{l}30-150(\mathrm{BID}) \\
50-450(\mathrm{QD}) \\
100 \text { for phase II studies }\end{array}$ & $\begin{array}{l}\text { NCT1915498 Patients with advanced hematologic malignancies and IDH2 } \\
\text { mutations (phase I/II) } \\
\text { NCT02273739 Patients with advanced solid tumors, including gliomas and } \\
\text { angioimmunoblastic T-lymphoma, and IDH2 mutations (phase I/II) } \\
\text { NCT02577406 Efficacy and safety of AG-221 versus conventional care regimens in } \\
\text { older patients with late-stage acute myeloid leukemia and IDH2 mutations (phase } \\
\text { I/II) } \\
\text { NCT02632708 Safety of AG-120 or AG-221 in combination with induction and } \\
\text { consolidation therapies in patients with newly diagnosed acute myeloid leukemia } \\
\text { and IDH1 or IDH2 mutations } \\
\text { NCT02677922 Safety and efficacy of AG-120+azacitidine or AG-221+azacitidine } \\
\text { in patients with newly diagnosed acute myeloid leukemia and IDH1 or IDH2 } \\
\text { mutations (phase I/II) }\end{array}$ \\
\hline AG-881 & IDH1/IDH2 & 5-100 (QD) & $\begin{array}{l}\text { NCT02492737 Patients with advanced hematologic malignancies and IDH1 or } \\
\text { IDH2 mutation (phase I) } \\
\text { NCT02481154 Patients with advanced solid tumors, including gliomas, and IDH1 } \\
\text { and/or IDH2 mutation (phase I) }\end{array}$ \\
\hline IDH305 & IDH1 & & $\begin{array}{l}\text { NCT02381886 Patients with advanced malignancies that harbor IDH1 mutations } \\
\text { (phase I) } \\
\text { NCT02826642 A dose-finding study of IDH305 with standard-of-care in IDH1 } \\
\text { mutant acute myeloid leukemia }\end{array}$ \\
\hline
\end{tabular}

. Abbreviations: QD: once per day; BID: twice per day.

pany focused on developing small-molecule and anticancer compounds that target cancer cell metabolism, which include drugs targeting mutant IDH1 and IDH2 enzymes.

\section{AG-120}

AG-120 is an IDH1-mutant-specific inhibitor, orally administered and currently being evaluated in multiple clinical trials involving various types of AML patients and IDH1-mutant-positive solid tumors, including glioma, chondrosarcoma and CCA (Table 2) (Fig. 4). Clinical data from an ongoing phase 1 dose-escalation trial in AML patients with clinically advanced (relapsing/refractory) disease were presented at the 2015 American Society of Hematology (ASH) Annual Meeting and provided evidence that mutant IDH1 is a valuable target in these AML patients. Specifically, it was reported that among 66 patients with relapsing/refractory AMLs bearing the IDH1 mutation, an overall response rate of $36 \%$ was observed, along with a complete remission rate of $18 \% .{ }^{102}$ Among the responders in this study, the median duration of response was 5.6 months. ${ }^{102}$ The follow-up of this study will reportedly involve three expansion cohorts, including patients with relapsing/refractory AMLs or with untreated AMLs, and other IDH1-mutationpositive patients with advanced hematologic malignancies. ${ }^{102}$

Clinical data from the dose-escalation portion of the ongoing phase 1 trial of AG-120 in solid tumors (20 gliomas and 35 non gliomas) were presented at the AACR-NCI-EORTC Meeting in
November 2015 and supported a well-tolerated safety profile for this drug and showed signals of clinical activity, sufficient to support additional future evaluation in patients with IDH1-mutant solid tumors. ${ }^{103}$ Particularly, 9 low grade and 11 grade III/IV glioma patients were enrolled in the phase I study with AG-120. AG-120 was found to be capable of lowering the levels of 2-HG in the brain. AG-120 administration was also found to be well tolerated, with no dose-limiting toxicity events being observed and with the observed adverse events mostly consisting of low-grade nausea, diarrhea, fatigue, vomiting, headache and peripheral edema. The dose level of $500 \mathrm{mg}$ twice daily was chosen for expansion cohorts. ${ }^{103}$ Among the patients with grade II gliomas, $66 \%$ responded to treatment, as evidenced by disease stabilization. One of the six patients with grade II gliomas displayed a marked reduction in tumor size. Moreover, $36 \%$ of the patients with grade III/IV gliomas responded to treatment, as indicated by disease stabilization. Of the 16 glioma patients evaluable over a longer period of time, $25 \%$ were without disease progression at the 6-month mark. ${ }^{103}$

\section{$A G-221$}

AG-221 is an orally administered, selective inhibitor of the IDH2mutant enzyme (Fig. 4). AG-221 has received the designations of 'orphan drug' and 'fast track' from the United States' Food and Drug Administration, and is currently under investigation in various types of patients bearing IDH2-mutated cancers, including 
relapsing/refractory AMLs and older relapsing/refractory AML patients (comprising a comparative study with conventional standard regimens, as frontline therapy of AML patients in combination with chemotherapy or 5'-azacytidine). Pre-clinical studies have supported a robust antitumor activity of AG-221, documented in primary AML blasts carrying the IDH2-R140Q mutation in xenograft models; specifically, administration of the drug was shown to confer a survival advantage and to induce differentiation of the grafted leukemic cells in vivo. ${ }^{104}$

Recent preliminary results of the first human phase I/II doseescalation study with AG-221 (Table 2) have been reported. ${ }^{105}$ Among the 128 cases of relapsing/refractory AMLs studied, $41 \%$ had objective responses, with a median response duration of 6.0 months. The response rates were found to be independent of the number of previous therapeutic regimens and of the molecular type of IDH2 mutation (either R140Q or R172K). Finally, 8 of the treated patients have been reported as ultimately requiring bone marrow transplantation. ${ }^{105}$

\section{$A G-811$}

The Agios Company also developed the AG-811 compound, an orally administered inhibitor exhibiting inhibitory activity against both IDH1 and IDH2-mutated enzymes. In preclinical studies, this inhibitor displayed the important property of fully penetrating the blood:brain barrier, thus offering the potential to treat glioma patients. Furthermore, this drug could represent a second-generation inhibitor for AG-120 and AG-221 in IDH-mutant tumors. Two types of clinical studies have been planned for this drug, one in patients with IDH-mutant solid tumors and one in patients with advanced hematologic malignancies who have progressed on a prior IDH inhibitor therapy (Table 2).

\section{IDH 305}

Another IDH1 inhibitor under clinical evaluation is IDH 305. IDH 305 specifically inhibits the IDH1-R132 mutant form. This drug is currently under evaluation in phase I/II clinical studies focusing on patients with advanced hematologic and solid IDH1-mutant tumors (Table 2).

\section{Alternative therapeutic strategies}

Some recent studies have shown that, in addition to the direct targeting of IDH-mutant enzymes, other biochemical pathways can be efficiently targeted in these leukemic cells to obtain a therapeutically significant effect. In this context, the study carried out by Chan and colleagues is particularly interesting. That study employed a large-scale RNA interference (RNAi) screen to identify genes that are synthetic lethal to IDH1-R132H; ultimately, the screen identified the $\mathrm{Bcl}-2$ gene. ${ }^{106}$ In line with these observations, both IDH1- and IDH2-mutant AML cells were found to be more sensitive to BCL-2 targeting than were the non IDH-mutant AML cells upon treatment with the small molecule inhibitor ABT-199. This BCL-2 inhibitor induced apoptosis of the leukemic cells. Collectively, the findings from that study indicated that the IDH $1 / 2$ mutation status identifies a subgroup of AMLs that are responsive to pharmacologic BCL-2 inhibition. ${ }^{106}$

Very interestingly, in a phase 1 clinical trial, treatment with BCL-2 inhibitor ABT-199 achieved complete responses in 5 of 32 AML patients, the majority of whom had relapsed/refractory leukemic disease; three of those 5 complete responders were IDHmutant AMLs. ${ }^{107}$ In addition, 3 of 11 AML patients with IDH mutations achieved a complete response following the ABT-199 treatment. ${ }^{107}$ Obviously, the number of treated patients is too low to support any conclusion about the clinical efficacy of BCL-2 inhibitors in IDH-mutant AMLs.

The studies carried out on IDH mutant AMLs are paradigmatic for demonstrating the key role of epigenetic modifiers on leukemia development and the therapeutic value of their targeting. In this context, particularly interesting and reminiscent of the observations made for IDH-mutant leukemic cells, are the results reported in a recent study showing that loss-of-function DNMT3A mutations can determine overexpression of the lysine methyltransferase DOT1L. ${ }^{108}$ Pharmacological inhibition of the DOT1L inhibitor EPZ5676 displayed antitumor activity in vivo, as evidenced in a nude rat xenograft model of DNMT3A-mutant AML. Specifically, the DOT1L inhibition elicited an antileukemic effect against primary DNMT3A-mutant AML cells, reducing their clonogenetic capacity and inducing their differentiation. ${ }^{108}$

Tateishi and colleagues have identified an alternative strategy to metabolically target IDH-mutant tumor cells. ${ }^{109}$ The initial analysis involved the effects of deregulated Myc that had been observed in many tumors, regarding the metabolic state; the features examined included increased glycolytic rate and glutaminolysis to meet the increased biosynthetic demand of cancer cells. This altered cell metabolism was proposed to render Myc-driven cancers particularly sensitive to nutrient deprivation. ${ }^{109}$ Using a panel of patientderived glioblastoma tumorsphere lines, the researchers showed that glycolytic inhibition using small molecule inhibitors of the $\mathrm{NAD}^{+}$salvage enzyme nicotinamide phosphoribosyl-transferase (NAMPT) may represent a powerful strategy to inhibit Myc-driven cancers. ${ }^{110}$ Given these observations, Tateishi and colleagues subsequently compared the metabolic profiles of IDH1-mutant glioma tumor initiating cells without and with IDH inhibition to identify potential metabolic vulnerabilities. ${ }^{111}$ The results demonstrated that IDH1-mutant cancer cells are extremely vulnerable to depletion of the coenzyme $\mathrm{NAD}^{+}$, a phenomenon that was likely due to the pronounced depletion of $\mathrm{NAD}^{+}$levels observed in these cells and due to the down-regulation of the inhibition of the $\mathrm{NAD}^{+}$ salvage pathway enzyme NAMPT. ${ }^{11} \mathrm{NAD}^{+}$depletion was also shown to activate an autophagic process, resulting in cytotoxicity. ${ }^{111}$ Since NAMPT inhibitors have entered clinical development, these findings have the potential perspective for rapid translation in IDH-mutant neoplasias. ${ }^{112}$

\section{Molecular imaging of IDH-mutant tumors}

The unique features of glucose, glutamine and lipid metabolism identified in IDH-mutant tumors can be exploited for molecular imaging of these tumors. This approach has important implications at the diagnostic level and represents a valuable tool for monitoring response to drug treatments. Furthermore, this tool has proven useful in preclinical studies of drug discovery, when applied to suitable animal models.

The molecular imaging of IDH-mutant tumors was investigated for human gliomas. Unfortunately, the markedly increased concentration of 2-HG exceeds the sensitivity threshold for in vivo magnetic resonance spectroscopy. ${ }^{113}$ Numerous studies have shown the feasibility of single voxel or single slice magnetic resonance spectroscopy (MRS) in vivo for detection of 2-HG in IDH-mutant gliomas of human patients. ${ }^{114-116}$ However, the in vivo detection of 2-HG by conventional MRS is challenging, and particular editing spectroscopic methods are required to unambiguously distinguish 
the true 2-HG signal from spurious overlapping signals caused by metabolites with similar chemical structures. ${ }^{117,118}$ Nonetheless, the 2-HG imaging approach has diagnostic/prognostic value for prediction of treatment outcome and for longitudinal monitoring of treatment response. ${ }^{117-119}$ The development of more sophisticated MRS techniques, such as three-dimensional (3D) MRS imaging sequence (MRSI), allow for selective editing of 2-HG, with increased temporal stability and spatial coverage. This technique was demonstrated as useful for the careful monitoring of response to standard therapy of IDH-mutant gliomas. ${ }^{120}$

Other studies have confirmed that 2-HG-MRS can be linked with routine MR imaging to provide a quantitative measurement of 2-HG content in gliomas, which represents a useful biomarker to monitor the abundance of noninvasive IDH-mutant tumor cells during glioma treatment. ${ }^{121}$ Interestingly, a recent analysis of the volumetric relationship between 2-HG-MRSI and standard MR imaging showed that, in about half of glioma patients, the 2-HG volumetric assessment of tumor burden is more extensive than that of the standard MR imaging volume, as assessed by fluid-attenuated inversion recovery (FLAIR) hyperintensity. ${ }^{122}$

The standard MRS technology commonly used in clinical studies implies a high-resolution magic angle spinning proton magnetic resonance spectroscopy $\left({ }^{1} \mathrm{H}-\mathrm{MRS}\right)$ at magnetic field strengths of 3T. Using this technique, the selective detection of 2-HG-related signals is challenging because of the overlapping signals that are generated by glutamine, glutamate, glutathione and $\gamma$-aminobutiric acid. This problem can be avoided, however, by using ultrahigh magnetic fields (UHF; $\geq 7 \mathrm{~T}$ ) because the in vivo ${ }^{1} \mathrm{H}-\mathrm{MRS}$ detection of 2-HG and other metabolites in this condition gains in signal-tonoise ratio and in spectral resolution, thus allowing the detection of small changes in 2-HG levels from small volumes of interest and with a higher specificity compared to techniques with the $3 \mathrm{~T}$ magnetic field. ${ }^{40}$ Using this improved technique, it was demonstrated that IDH2-mutant gliomas produced more 2-HG than IDH1-mutant tumors. ${ }^{40}$ Importantly, this technology offers the opportunity to quantify the neurochemical profiles of at least eight metabolites, including 2-HG, glutamate, glutamine, lactate and glutathione, in both tumoral and normal tissues. ${ }^{40}$ Other studies have confirmed the efficacy of 7T MRS for in vivo detection of 2-HG in brain tumors, with discrimination of this metabolite from glutamine, glutamate and GABA. ${ }^{123}$

Finally, the in vivo imaging of IDH-mutant tumors may have a fundamental impact on the discovery of new drugs with inhibitory activity against these tumors. Indeed, in vitro and in vivo monitoring of 2-HG levels have led to the discovery Zaprinast, a phosphodiesterase 5 inhibitor, as a glutaminase inhibitor acting as an efficacious modulator of $2-\mathrm{HG}$ production. ${ }^{124}$ For experimental studies, bioluminescence techniques on tumor biopsies allowed for the determination of 2-HG, ATP, glucose, pyruvate, and lactate by quantitative imaging. ${ }^{125}$ Finally, this technique allows for evaluation of the metabolic profile of individual tumors and the potential effect of some inhibitory drugs. ${ }^{125}$

\section{Conclusions}

In conclusion, the studies carried out in the last few years have shown that, while normal IDH enzymes catalyze the oxidative decarboxylation of isocitric acid to produce $\alpha-\mathrm{KG}$, the mutant IDH1 and IDH2 enzymes lose this function and catalyze a new reaction, namely the reduction of $\alpha-\mathrm{KG}$ to D-2-HG. This neomorphic function leads to the generation of markedly increased levels of this anomalous metabolite (i.e. D-2-HG), which is present only in trace amounts in normal cells. D-2-HG was found to inhibit $\alpha-\mathrm{KG}$ dependent KDMs and the TET family of 5-methylcytosine hydroxylases, with consequent hypermethylation of histones and DNA. These molecular events are responsible for the blockade of cell differentiation observed in IDH-mutant tumors. Studies of the molecular evolution of IDH-mutant AMLs and gliomas strongly support the view that IDH mutations are early driver events promoting the initial steps of tumor development and are fully maintained during tumor progression, therefore representing ideal targets for therapeutic purposes.

These observations have provided evidence that strongly supports the notion that IDH mutations will be effective drug targets for intervention. A number of potent and selective inhibitors of mutant IDH1 and IDH2 have been synthesized and characterized in detail. Some of these inhibitors have entered active programs of clinical development and are currently under investigation in phase I/II studies on IDH-mutant tumors, including AMLs, gliomas, CCAs and chondrosarcomas. Two of these inhibitors, in particular, AG-221 and AG-120, have exhibited promising clinical pharmacokinetic, safety and efficacy profiles.

\section{Conflict of interest}

The authors have no conflict of interests related to this publication.

\section{Author contributions}

Preparation of the manuscript including Tables and Figures (EP, GC, UT).

\section{References}

[1] Xu X, Zhao J, Xu Z, Peng B, Huang Q, Arnold E, et al. Structures of human cytosolic NADP-dependent isocitrate dehydrogenase reveal a novel selfregulatory mechanism of activity. J Biol Chem 2004;279(32):33946-33957. doi:10.1074/jbc.M404298200.

[2] Ceccarelli C, Grodsky NB, Ariyaratne N, Colman RF, Behnson BJ. Crystal structure of porcine mitochondrial $\mathrm{NADP}^{+}$-dependent isocitrate dehydrogenase complexed with $\mathrm{Mn}^{2+}$ and isocitrate. Insights into the enzyme mechanism. J Biol Chem 2002;277(45):43454 43562. doi:10.1074/jbc.M207306200.

[3] Lewis CA, Parker SJ, Fiske BP, McCloskey D, Gui DY, Green CR, et al. Tracing compartimentalized NADPH metabolism in the cytosol and mitochondria of mammalian cells. Mol Cell 2014;55(2):253-263. doi:10.1016/j.molcel.2014.05.008.

[4] Bleeker FE, Atai NA, Lamba S, Jonker A, Rijkeboer D, Bosch KS, et al. The prognostic IDH1 (R132) mutation is associated with reduced $\mathrm{NADP}^{+}$-dependent IDH activity in glioblastoma. Acta Neuropathol 2010;119(4):487-494 doi:10.1007/s00401-010-0645-6.

[5] Parker SJ, Metallo CM. Metabolic consequences of oncogenic IDH mutations. Pharmacol Ther 2015;152:54-62. doi:10.1016/j.pharmthera.2015.05.003.

[6] Dang L, White DW, Gross S, Bennett BD, Bittinger MA, Driggfers EM, et al. Cancer-associated IDH1 mutations produce 2-hydroxyglutarate. Nature 2009;462(7274):739-744 doi:10.1038/nature08617.

[7] Ward PS, Patel J, Wise DR, Abdel-Wahab O, Bennett BD, Coller HA, et al. The common feature of leukemia-associated IDH1 and IDH2 mutations is a neomorphic enzyme activity converting alpha-ketoglutarate to 2-hydroxyglutarate. Cancer Cell 2010;17(3):225-234. doi:10.1016/j.ccr.2010.01.020.

[8] Reitman ZJ, Jin G, Karoly ED, Spasojevic I, Yang J, Kinzler KW, et al. Profiling the effects of isocitrate dehydrogenase 1 and 2 mutations on the cellular metabolome. Proc Natl Acad Sci U S A 2011;108(8):3270-3275. doi:10.1073/ pnas. 1019393108.

[9] Seltzer MJ, Bennett BD, Joshi AD, Gao P, Thomas AG, Ferraris DV, et al. Inhibition of glutaminase preferentially slows growth of glioma cells with mutant IDH1. Cancer Res 2010;70(22):8981-8987. doi:10.1158/0008-5472.CAN-101666.

[10] Leonardi R, Subramanian C, Jackowski S, Rock CO. Cancer-associate isocitrate dehydrogenase mutations inactivate NADPH-dependent reductive carboxyla- 
tion. J Biol Chem 2012;287(18):14615-14620. doi:10.1074/jbc.C112.353946.

[11] Grassian AR, Parker SJ, Davidson SM, Divakaruni AS, Green CR, Zhang X, et al. IDH1 mutations alter citric acid cycle metabolism and increase dependence an oxidative mitochondrial metabolism. Cancer Res 2014;74(12):3317-3331. doi:10.1158/0008-5472.CAN-14-0772-T.

[12] Amary MF, Bacsi K, Maggiani F, Damato S, Halai D, Berisha F, et al. IDH1 and IDH2 mutations are frequent events in central chondrosarcoma and central and periosteal chondromas but not in other mesenchymal tumors. J Pathol 2011;224(3):334-343. doi:10.1002/path.2913.

[13] Damato S, Alorjani M, Bonar F, McCarthy SW, Cannon SR, O'Donnell P, et al. IDH1 mutations are not found in cartilaginous tumors other than central and periosteal chondrosarcomas and enchondromas. Histopathology 2012;60(2):363-365. doi:10.1111/j.1365-2559.2011.04010.x.

[14] Amary MF, Damato S, Halai D, Eskandarpour M, Berisha F, Bonar F, et al. Ollier disease and Maffucci syndrome are caused by somatic mosaic mutations of IDH1 and IDH2. Nat Genet 2011;43(12):1262-1265. doi:10.1038/ng.994.

[15] Hirata M, Sasaki M, Cairns RA, Inoue S, Puviindran V, Li WY, et al. Mutant IDH is sufficient to initiate enchondromatosis in mice. Proc Natl Acad Sci U S A 2015;112(9):2829-2834. doi:10.1073/pnas.1424400112.

[16] Asp J, Sangiorgi L, Inerot SE, Lindahl A, Molendini L, Benassi MS, et al. Changes of the p16 gene but the p53 gene in human chondrosarcoma tissues. Int J Cancer 2000;85(6):782-786. doi:10.1002/(SICI)1097-0215(20000315) 85:6<782::AID-IJC7>3.0.CO;2-O.

[17] Bonnet C, Thomas L, Psimaras D, Bielle F, Vauleon E, Loiseau H, et al. Characteristics of gliomas in patients with somatic IDH mosaicism. Acta Neropathol Commun 2016;4:31. doi:10.1186/s40478-016-0302-y.

[18] Na KY, Noh BJ, Sung JY, Kim YW, Santini Arajuo E, Park YK. IDH mutation analysis in Ewing sarcoma family tumors. J Pathol Transl Med 2015;49(3):257261. doi:10.4132/jptm.2015.04.14.

[19] Jin Y, Elalaf H, Watanabe M, Tamaki S, Hineno S, Matsumaga K, et al. Mutant IDH1 dysregulates the differentiation of mesenchymal stem cells in association with gene-specific histone modifications in cartilage- and bone-related genes. PLoS One 2015;10(7):e0131998. doi:10.1371/journal.pone.0131998.

[20] Li L, Paz AC, Wilky BA, Johnson B, Galoian K, Rosenberg A, et al. Treatment with a small molecular mutant IDH1 inhibitor suppresses tumorigenic activity and the production of the oncometabolite 2-hydroxyglutarate in human chondrosarcoma cells. PLoS One 2015;10(9):e0133813. doi:10.1371/journal. pone. 0133813 .

[21] Kaneko MK, Liu X, Oki H, Ogasawara S, Nakamura T, Saidoh N, et al. Isocitrate dehydrogenase mutation is frequently observed in giant cell tumor of bone. Cancer Sci 2014;105(6):744-748. doi:10.1111/cas.12413.

[22] Liu X, Kato Y, Kaneko MK, Sugawara M, Ogasawara S, Tsujimoto Y, et al. Isocitrate dehydrogenase 2 mutation is a frequent event in osteosarcoma detected by a multi-specific monoclonal antibody MsMasb1. Cancer Med 2013;2(6):803-814. doi:10.1002/cam4.149.

[23] Yan H, Parson DW, Jin G, McLendon R, Rasheed BA, Yuan W, et al. IDH1 and IDH2 mutations in gliomas. N Engl J Med 2009;360(8):765-773. doi:10.1056/ NEJMoa0808710.

[24] Ohgaki H, Kleihues P. The definition of primary and secondary glioblastoma Clin Cancer Res 2013;19(4):764-772. doi:10.1158/1078-0432.CCR-12-3002.

[25] Hartmann C, Meyer J, Balss J, Copper D, Mueller W, Christians A, et al. Type and frequency of IDH1 and IDH2 mutations are related to astrocytic and oligodendroglial differentiation and age: a study of 1,010 diffuse gliomas. Acta Neuropathol 2009;118(4):469-474. doi:10.1007/s00401-009-0561-9.

[26] Nobusawa S, Watanabe T, Kleihues P, Ohgaki H. IDH1 mutations as molecular signature and predictive factor of secondary glioblastomas. Clin Cancer Res 2009;15(19):6002-6007. doi:10.1158/1078-0432.CCR-09-0715.

[27] Watanabe T, Nobusawa S, Kleihues P, Ohgaki H. IDH1 mutations are early events in the development of astrocytomas and oligodendrogliomas. Am J Pathol 2009;174(4):1149-1153. doi:10.2353/ajpath.2009.080958.

[28] Lai A, Kharbanda S, Pope WB, Tran A, Solis OE, Peale F, et al. Evidence for sequenced molecular evolution of IDH1 mutant glioblastoma from a distinct cell of origin. J Clin Oncol 2011;29(34):4482-4490. doi:10.1200/ JCO.2010.33.8715.

[29] Rohle D, Popovici-Muller J, Palaskas N, Turcan S, Grommes C, Campos C, et al. Inhibitor of mutant IDH1 delays growth and promotes differentiation of glioma cells. Science 2013;340(6132):626-630. doi:10.1126/science.1236062.

[30] Eckel-Passow JE, Lachance DH, Molinaro AM, Walsh KM, Decker PA, Sciotte $\mathrm{H}$, et al. Glioma groups based on 1p/19q, IDH and TERT promoter mutations in tumors. N Engl J Med 2015;372(26):2499-2508. doi:10.1056/NEJMoa1407279.

[31] Leu S, von Felten S, Frank S, Boulay JL, Mariani L. IDH mutation is associated with higher risk of malignant transformation in low-grade glioma. J Neurooncol 2016;127(2):363-372. doi:10.1007/s11060-015-2048-y.

[32] Cancer Genome Atlas Research Network, Brat DJ, Verhaak RG, Aldape KD, Young WK, Salama SR, et al. Comprehensive integrative genomic analysis of diffuse lower-grade gliomas. N Engl J Med 2015;372(26):2481-2498. doi:10.1056/NEJMoa1402121.

[33] Ceccarelli M, Barthel FP, Malta T, Sabedot T, Salama SR, Murray BA, et al. Molecular profiling reveals biologically discrete subsets and pathways of progression in diffuse glioma. Cell 2016;164(3):550-563. doi:10.1016/j. cell.2015.12.028

[34] Bai H, Harmanci AS, Erson-Omay EZ, Li J, Coskun S, Simon M, et al. Integrated genomic characterization of IDH-mutant glioma malignant progression. Nat Genet 2016;48(1):59-66. doi:10.1038/ng.3457.

[35] Mandel JJ, Cachia D, Liu D, Wilson C, Aldape K, Fuller G, et al. Impact of IDH-1 mutation status on outcome in clinical trials for recurrent glioblastoma. J Neurooncol 2016;129(1):147-154. doi:10.1007/s11060-016-2157-2.

[36] Lin X, Brennan C, Zehir A, Berger M; Solit D, Hyman D, et al. Genomic profile, radiological and clinical features of IDH Wild-Type WHO grades II and III glioma (P5.254). Neurology 2016;86(16Supplement):P5.254.

[37] Brennan CW, Verhaak RG, McKenna A, Campos B, Noushmehr H, Seloma SR, et al. The somatic genomic landscape of glioblastoma. Cell 2013;155(2):462477. doi:10.1016/j.cell.2013.09.034.

[38] Flavahan WA, Drier Y, Lian BB, Gillespie SM, Venteicher AS, Stemmer-Rachamimov AO, et al. Insulator dysfunction and oncogene activation in IDH mutant gliomas. Nature 2016;529(7584):110-114. doi:10.1038/nature16490.

[39] Fathi AT, Nahed BV, Wander SA, Iafrate AJ, Borger DR, Hu R, et al. Elevation of urinary 2-hydroxyglutarate in IDH-mutant glioma. Oncologist 2016;21(2):214-219. doi:10.1634/theoncologist.2015-0342.

[40] Emir UE, Larkin SJ, de Pennigton N, Voets N, Plaha P, Stacey R, et al. Noninvasive quantification of 2-hydroxyglutarate in human gliomas with IDH1 and IDH2 mutation. Cancer Res 2016;76(1):43-49. doi:10.1158/0008-5472.CAN15-0934.

[41] Zeng A, Hu Q, Liu Y, Wang Z, Cui X, Li R, et al. IDH1/2 mutation status combined with Ki67 labeling index defines distinct prognostic groups in glioma. Oncotarget 2015;6(30):30232-30238. doi:10.18632/oncotarget.4920.

[42] Ebrahimi A, Skardelly M, Bonzheim I, Ott I, Mühleisen H, Eckert F, et al. ATRX immunostaining predicts IDH and H3F3A status in gliomas. Acta Neuropathol Commun 2016;4(1):60. doi:10.1186/s40478-016-0331-6.

[43] Leeper HE, Caron AA, Decker PA, Jemkins RB, Lachance DH, Giannini C. IDH mutation, $1 \mathrm{p} 19 \mathrm{q}$ codeletion and ATRX loss in WHO grade II gliomas. Oncotarget 2015;6(30):30295-30305. doi:10.18632/oncotarget.4497.

[44] Li F, He X, Ye D, Lin Y, Yu H, Yao C, et al. NADP ${ }^{+}$-IDH mutations promote hypersuccinylation that impairs mitochondria respiration and induces apoptosis resistance. Mol Cell 2015;60(4):661-675. doi:10.1016/j.molcel.2015.10.017.

[45] Zhou L, Wang F, Sun R, Chen X, Zhang M, Xu Q, et al. SIRT5 promotes IDH2 desuccinylation and G6PD deglutarylation to enhance cellular antioxidant defense. EMBO Rep 2016;17(6):811-822. doi:10.15252/embr.201541643.

[46] Mardis ER, Ding L, Dooling DJ, Larson DE, McLellan MD, Chen K, et al. Recurring mutations found by sequencing an acute myeloid leukemia genome. N Engl J Med 2009;361(11):1058-1066. doi:10.1056/NEJMoa0903840.

[47] Cancer Genome Atlas Research Network. Genomic and epigenomic landscapes of adult de novo acute myeloid leukemia. N Engl J Med 2013;368(22):20592074. doi:10.1056/NEJMoa1301689.

[48] Paschka P, Schlenk RF, Gaidzik VI, Habdank M, Krönke J, Bullinger L, et al. IDH1 and IDH2 mutations are frequent genetic alterations in acute myeloid leukemia and confer adverse prognosis in cytogenetically normal acute myeloid leukemia with NPM1 mutation without FLT3 internal tandem duplication. J Clin Oncol 2010;28(22):3636-3643. doi:10.1200/JCO.2010.28.3762.

[49] Marcucci G, Maharry K, Wu YZ, Radmacher MD, Mrózek K, Margeson D, et al. IDH1 and IDH2 gene mutations identify novel molecular subsets within de novo cytogenetically normal acute myeloid leukemia: a cancer and leukemia group B study. J Clin Oncol 2010;28(14):2348-2355. doi:10.1200/ JCO.2009.27.3730.

[50] Patel JP, Gönen M, Figueroa ME, Fernandez H, Sun Z, Racevskis J, et al. Prognostic relevance of integrated genetic profiling in acute myeloid leukemia. N Engl J Med 2012;366(12):1079-1089. doi:10.1056/NEJMoa1112304.

[51] Rampal R, Alkalin A, Madzo J, Vasanthakumar A, Pronier E, Patel J, et al. DNA hydroxymethylation profiling reveals that WT1 mutations result in loss of TET2 function in acute myeloid leukemia. Cell Rep 2014;9(5):1841-1855. doi:10.1016/j.celrep.2014.11.004

[52] Im AP, Sehgal AR, Carroll MP, Smith BD, Tefferi A, Johnson DE, et al. DNMT3A and IDH mutations in acute myeloid leukemia and other myeloid malignancies: associations with prognosis and potential treatment strategies. Leukemia 2014;28(9):1774-1783. doi:10.1038/leu.2014.124.

[53] Di Nardo CD, Rawandi F, Agresta S, Knopleva M, Takahashi K, Kadia T, et al. Characteristics, clinical outcome and prognostic significance of IDH mutations in AML. Am J Haematol 2015;90(8):732-736. doi:10.1002/ajh.24072.

[54] Gross S, Cairns RA, Minden MD, Driggles EM, Bittinger MA, Jang HG, et al. Cancer-associated metabolite 2-hydroxyglutarate accumulates in acute myelogenous leukemia with isocitrate dehydrogenase 1 and 2 mutations. J Exp Med 2010;207(2):339-344. doi:10.1084/jem.20092506.

[55] Leonarz C, Schofield CJ. Expanding chemical biology of 2-oxoglutarate oxygenases. Nat Chem Biol 2008;4(3):152-156. doi:10.1038/nchembio0308-152.

[56] Xu W, Yang H, Liu Y, Yang Y, Wang P, Kim SH, et al. Oncometabolite 2-hydroxyglutarate is a competitive inhibitor of $\alpha$-ketoglutarate-dependent dioxygenases. Cancer Cell 2011;19(1):17-30. doi:10.1016/j.ccr.2010.12.014.

[57] Heuser M, Araujo Cruz MM, Goparaju R, Chaturvedi A. Enigmas of IDH mutations in hematology/oncology. Exp Hematol 2015;43(8):685-697. 
doi:10.1016/j.exphem.2015.05.005.

[58] Chaturvedi A, Araujo Cruz MM, Jyotsana N, Sharma A, Goparaju R, Schwarzer A, et al. Enantiomer-specific and paracrine leukemogenicity of mutant IDH metabolite 2-hydroxyglutarate. Leukemia 2016;30(8):1708-1715. doi:10.1038/ leu.2016.71.

[59] Janin M, Mylossasa E, Saada V, Micol JB, Renneville A, Quovoron C, et al. Serum 2-Hydroxyglutarate production in IDH1- and IDH2-mutated de novo acute leukemia French Association Group. J Clin Oncol 2013;32(4):297-305. doi:10.1200/JCO.2013.50.2047.

[60] Balss J, Thiede C, Bochtler T, Okun JG, Saadati M, Benner A, et al. Pretreatment D-2-hydroxyglutarate serum levels negatively impact on outcome in IDH1-metated acute myeloid leukemia. Leukemia 2016;30(4):782-788. doi:10.1038/leu.2015.317.

[61] Figueroa ME, Abdel-Wahab O, Lu C, Ward PS, Patel J, Shih A, et al. Leukemic IDH1 and IDH2 mutations result in a hypermethylation phenotype, disrupt TET2 function, and impair hematopoietic differentiation. Cancer Cell 2010;18(6):553-567. doi:10.1016/j.ccr.2010.11.015.

[62] Sasaki M, Knobbe C, Munger JC, Lind EF, Brenner D, Brustle A, et al. IDH1(R132H) mutation increases murine hematopoietic progenitors and alters epigenetics. Nature 2012;488(7413):656-659. doi:10.1038/nature11323.

[63] Losman JA, Cooper RE, Koivunen P, Lee S, Schneider RK, McMahon C, et al. R)-2-Hydroxyglutarate is sufficient to promote leukemogenesis and its effects are reversible. Science 2013;339(6127):1621-1625. doi:10.1126/science. 1231677.

[64] Duncan CG, Barwick BG, Jin G, Rogo C, Kapoor-Varizoni P, Powell DR, et al. A heterozygous IDH1 R132H/WT mutation induces genome-wide alterations in DNA methylation. Genome Res 2012;22(12):2339-2355. doi:10.1101/ gr.132738.111.

[65] Chou AP, Chowdhury R, Li S, Chen W, Kim AJ, Piccioni DE, et al. Identification of retinol binding protein 1 promoter hypermethylation in isocitrate dehydrogenase 1 abd 2 mutant gliomas. J Natl Cancer Inst 2012;104(19):14581469. doi:10.1093/jnci/djs357.

[66] Guilhamon P, Eskandorpour M, Halai D, Wilson GA, Feber A, Teschendorff $\mathrm{AE}$, et al. Meta-analysis of IDH-mutant cancers identifies EBF1 as an interaction partner for TET2. Nat Commun 2013;4:2166. doi:10.1038/ncomms3166.

[67] Boutzen H, Saland E, Larrue C, de Toni F, Gales L, Castelli FA, et al. Isocitrate dehydrogenase 1 mutations prime the all-trans retinoic acid myeloid differentiation pathway in acute myeloid leukemia. J Exp Med 2016;213(4):483-497. doi:10.1084/jem.20150736.

[68] Wang F, Travins J, DeLaBarre B, Penard-Lacronique V, Schalm S, Hansen E, et al. Targeted inhibition of mutant IDH2 in leukemia cells induces cellular differentiation. Science 2013;340(6132):622-626. doi:10.1126/science.1234769.

[69] Inoue S, Li WY, Tseng A, Beerman I, Elia AJ, Bendall SC, et al. Mutant IDH1 downregulates ATM and alters repair and sensitivity to DNA damage independent of TET2. Cancer Cell 2016;30(2):337-348. doi:10.1016/j. ccell.2016.05.018.

[70] Chaturvedi A, Araujo Cruz MM, Jyotsana N, Sharma A, Yun H, Görlich K, et al. Mutant IDH1 promotes leukemogenesis in vivo and can be specifically targeted in human AML. Blood 2013;122(16):2877-2887. doi:10.1182 blood-2013-03-491571.

[71] Chen C, Liu Y, Lu C, Cross JR, Morris JP4th, Shroff AS, et al. Cancer-associated IDH2 mutants drive an acute myeloid leukemia that is susceptible to Brd4 inhibition. Genes Dev 2013;27(18):1974-1985. doi:10.1101/gad.226613.113.

[72] Kats LM, Reschke M, Taulli R, Pozdnyakova O, Burgess K, Bhargava P, et al. Proto-oncogenic role of mutant IDH2 in leukemia initiation and maintenance. Cell Stem Cell 2014;14(3):329-341. doi:10.1016/j.stem.2013.12.016.

[73] Ogawara Y, Katsumoto T, Aikawa Y, Shima Y, Kagiyama Y, Soga T, et al. IDH2 and NPM1 mutations cooperate to activate Hoxa9/Meis1 and hypoxia pathways in acute myeloid leukemia. Cancer Res 2015;75(10):2005-2016. doi:10.1158/0008-5472.CAN-14-2200.

[74] Corces-Zimmerman MR, Majeti R. Pre-leukemic evolution of hematopoietic stem cells: the importance of early mutations in leukemogenesis. Leukemia 2014;28(12):2276-2282. doi:10.1038/leu.2014.211.

[75] Corces-Zimmerman MR, Hong WJ, Weissman IL, Medeiros BC, Majeti R. Preleukemic mutations in human acute myeloid leukemia affect epigenetic regulators and persist in remission. Proc Natl Acad Sci U S A 2014;111(7):25482553. doi:10.1073/pnas.1324297111.

[76] Chan SM, Majeti R. Role of DNMT3A, TET2, and IDH1-2 mutations in preleukemic stem cells in acute myeloid leukemia. Int J Hematol 2013;98(6):648657. doi:10.1007/s12185-013-1407-8.

[77] Sykes SM, Kokkaliaris KD, Milsom MD, Levine RL, Majeti R. Clonal evolution of preleukemic hematopoietic stem cells in acute myeloid leukemia. Exp Hematol 2015;43(12):989-992. doi:10.1016/j.exphem.2015.08.012.

[78] Patnaik MM, Hanson CA, Hodnefield JM, Laso TL, Finke CM, Knudson RA, et al. Differential prognostic effect of IDH1 versus IDH2 mutations in myelodysplastic syndromes: a Mayo clinic study of 277 patients. Leukemia 2012;26(1):101-105. doi:10.1038/leu.2011.298.

[79] Lin CC, Hou HA, Chou WC, Kuo YY, Liu CY, Chen CY, et al. IDH mutations are closely associated with mutations of DNMT3A, ASXL1 and SRSF2 in patients with myelodysplastic syndromes and are stable during disease evolution.
Am J Hematol 2014;89(2):137-144. doi:10.1002/ajh.23596.

[80] DiNardo CD, Jabbour E, Ravandi F, Takahashi K, Daver N, Routbort M, et al. IDH1 and IDH2 mutations in myelodysplastic syndromes and role in disease progression. Leukemia 2016;30(4):980-984. doi:10.1038/leu.2015.211.

[81] Lin TL, Nagata Y, Kao HW, Sanada M, Okuno Y, Huang CF, et al. Clonal leukemic evolution in myelodysplastic syndromes with TET2 and IDH1/2 mutations. Haematologica 2014;99(1):28-36. doi:10.3324/haematol.2013.091249.

[82] Tefferi A, Lasho TL, Abdel-Wahab O, Guglielminelli P, Patel J, Caramaz za D, et al. IDH1 and IDH2 mutation studies in 1473 patients with chronic-, fibroticor blast-phase essential thromobocytopenia, polycythemia vera or myelofibrosis. Leukemia 2010;24(7):1302-1309. doi:10.1038/leu.2010.113.

[83] Tefferi A, Jimma T, Sulai NH, Lasho TL, Finke CM, Knudson RA, et al. IDH mutations in primary myelofibrosis predict leukemic transformation and shortned survival: clinical evidence for leukemogenic collaboration with JAK2V617F. Leukemia 2012;26(3):475-480. doi:10.1038/leu.2011.253.

[84] Vannucchi AM, Lasho TL, Guglielminelli P, Biamonte F, Pardanani A, Pereira $\mathrm{A}$, et al. Mutations and prognosis in primary myelofibrosis. Leukemia 2013;27(9):1861-1869. doi:10.1038/leu.2013.119.

[85] Yonal-Hindilerden I, Daglar-Aday A, Hindilerden F, Akadam-Teker B, Yilmaz $\mathrm{C}$, Nalcaci $\mathrm{M}$, et al. The clinical significance of IDH mutations in essential thrombocytopenia and primary myelofibrosis. J Clin Med Res 2016;8(1):2939. doi:10.14740/jocmr2405w.

[86] Cairns RA, Iqbal J, Lemonnier F, Kucubuk C, deLaval L, Jais JP, et al. IDH2 mutations are frequent in angioimmunoblastic T-cell lymphoma. Blood 2012;119(8):1901-1903. doi:10.1182/blood-2011-11-391748.

[87] Sakata-Yanagimoto M, Enami T, Yoshida K, S hiraishi Y, Ishii R, Miyake Y, et al. Somatic RHOA mutation in angioimmunoblastic T cell lymphoma. Nat Genet 2014;46(2):171-175. doi:10.1038/ng.2872.

[88] Odejide O, Weigert O, Lane AA, Toscano D, Lunning M, Kopp N, et al. A targeted mutational landscape of angioimmunoblastic T-cell lymphoma. Blood 2014;123(9):1293-1296. doi:10.1182/blood-2013-10-531509.

[89] Wang C, McKeithan TW, Gong Q, Zhang W, Bouska A, Rosenwald A, et al. $\mathrm{IDH} 2^{\mathrm{R} 172}$ mutations define a unique subgroup of patients with angioimmunoblastic T-cell lymphoma. Blood 2015;126(15):1741-1752. doi:10.1182 blood-2015-05-644591.

[90] Borger DR, Tanabe KK, Fan KC, Lopez HU, Fantin VR, Straley KS, et al. Frequent mutation of isocitrate dehydrogenase IDH(1) and IDH2 in cholangiocarcinoma identified through broad-based tumor genotyping. Oncologist 2012;17(1):72-79. doi:10.1634/theoncologist.2011-0386.

[91] Kipp BR, Voss JS, Kerr SE, Barr Fritcher EG, Graham RP, Zhang L, et al. Isocitrate dehydrogenase 1 and 2 mutations in cholangiocarcinoma. Hum Pathol 2012;43(10):1552-1558. doi:10.1016/j.humpath.2011.12.007.

[92] Wang P, Dong Q, Zhang C, Kuan PF, Liu Y, Jeck WR, et al. Mutations in isocitrate dehydrogenase 1 and 2 occur frequently in intrahepatic cholangiocarcinomas and share hypermethylation targets with glioblastomas. Oncogene 2013;32(25):3091-3100. doi:10.1038/onc.2012.315.

[93] Goyal L, Govindan A, Sheth RA, Nardi V, Blaszowsky LS, Faris JE, et al. Prognosis and clinicopathologic features of patients with advanced stage isocitrate dehydrogenase (IDH) mutant and IDH wild-type intrahepatic cholangiocarcinoma. Oncologist 2015;20(9):1019-1027. doi:10.1634/theoncologist.2015-0210.

[94] Fujimoto A, Furuta M, Shiraishi Y, Gotoh K, Kukakami Y, Arihiro K, et al Whole-genome mutational landscape of liver cancers displaying biliary phenotype reveals hepatitis impact and molecular diversity. Nat Commun 2015;6:6120. doi:10.1038/ncomms 7120

[95] Hayashi A, Misumi K, Shihabara J, Arita J, Sakamoto Y, Hasegawa K, et al. Distinct clinicopathologic and genetic features of 2 histologic subtypes of intrahepatic cholangiocarcinoma. Am J Surg Pathol 2016;40(8):1021-1030. doi:10.1097/PAS.0000000000000670.

[96] Saha SK, Parachoniak CA, Ghanta KS, Fitamant J, Ross KN, Najem MS, et al. Mutant IDH inhibits HNF- $4 \alpha$ to block hepatocyte differentiation and promote biliary cancer. Nature 2014;513(7516):110-114. doi:10.1038/nature13441

[97] Saha SK, Garland JD, Kleinstiver BP, Vu P, Najem MS, Yeo JC, et al. Isocitrate dehydrogenase mutations confer dasatinib hypersensitivity and SRC dependence in intrahepatic cholangiocarcinoma. Cancer Discover 2016;6(7):727-739. doi:10.1158/2159-8290.CD-15-1442.

[98] Popovici-Muller J, Saunders JO, Salituro FG, Travins JM, Yan S, Zhao F, et al. Discovery of the first potent inhibitors of mutant IDH1 that lower tumor 2-HG in vivo. ACS Med Chem Lett 2012;3(10):850-855. doi:10.1021/ml300225h.

[99] Davis MI, Gross S, Shen M, Straley KS, Pragani R, Lea WA, et al. Biochemical, cellular and biophysical characterization of a potent inhibitor of mutan isocitrate dehydrogenase IDH1. J Biol Chem 2014;289(20):13717-13725 doi:10.1074/jbc.M113.511030.

[100] Deng G, Shen J, Yin M, McManus J, Mathieu M, Gee P, He T, et al. Selective inhibition of mutant isocitrate dehydrogenase 1 (IDH1) via disruption of a metal binding network by an allosteric small molecule. J Biol Chem 2015;290(2):762-774. doi:10.1074/jbc.M114.608497.

[101] Okoye-Okafor UC, Bartholdy B, Cartier J, Gao EN, Pietrak B, Rendina AR, et al. New IDH1 mutant inhibitor for treatment of acute myeloid leukemia. Nat Chem Biol 2015;11(11):878-886. doi:10.1038/nchembio.1930. 
[102] DiNardo C, de Botton S, Pollyea DA, Stein EM, Fathi AT, Roboz GJ, et al. Clinical response in patients with IDH1 mutation-positive hematologic malignancies receiving AG-120, a first-in-class potent inhibitor of mutant IDH1, in addition to data from the completed dose-escalation portion of the phase 1 study. Blood 2015;126:1306.

[103] Burris H, Mellinghoff I, Maher E, Wen P, Beeram M, Touat M, et al. The first reported results of AG-120, a first-in-class, potent inhibitor of the IDH1 mutant protein, in a Phase 1 study of patients with advanced IDH1-mutant solid tumors, including gliomas. Proceedings of the AACRNCI-EORTC International Conference: Molecular Targets and Cancer Therapeutics. 2015:5-9.

[104] Wang F, Travins J, Chen Y, Yang H, Straley K, Choe S, et al. AG-221 offers a survival advantage in a primary human $\mathrm{iDH} 2$ mutant $\mathrm{AML}$ xenograft model. Blood 2013;122(21):240.

[105] Stein EM, DiNardo C, Altman JK, Collins R, DeAngelo DJ, Kantarjian HM, et al. Safety and efficacy of AG-221, a potent inhibitor of mutant IDH2 that promotes differentiation of myeloid cells in patients with advanced hematologic malignancies: results of a phase $1 / 2$ trial. Blood 2015;126(23):323-323.

[106] Chan SM, Thomas D, Corces-Zimmerman M, Xavy S, Rastogi S, Hong WJ, et al. Isocitrate dehydrogenase 1 and 2 mutations induce BCL-2 dependence in acute myeloid leukemia. Nat Med 2015;21(2):178-184. doi:10.1038/nm.3788.

[107] Konopleva M, Pollyea DA, Potluri J, Chyla BJ, Busman T, McKeegan E, et al. A phase 2 study of ABT-199 (GDC-0199) in patients with Acute Myelogenous Leukemia (AML). Blood 2014;124(21):118.

[108] Rau RE, Rodriguez B, Luo M, Jeong M, Rosen A, Rogers JH, et al. DOT1L as a therapeutic target for the treatment of DNMT3A-mutant acute myeloid leukemia. Blood 2016;128(7):971-981. doi:10.1182/blood-2015-11-684225.

[109] Wise DR, DeBernardinis RJ, Mancuso A, Sayed N, Zhang XY, Pfeiffer HK, et al. Myc regulates a transcriptional program that stimulates mitochondrial glutaminolysis and leads to glutamine addiction. Proc Natl Acad Sci U S A 2008;105(48):18782-18787. doi:10.1073/pnas.0810199105.

[110] Tan B, Yong DA, Lu ZH, Wang T, Meil TI, Shepard RL, et al. Pharmacological inhibition of nicotinamide phosphoribosyltransferase (NAMPT), an enzyme essential for $\mathrm{NAD}^{+}$biosynthesis, in human cancer cells: metabolic basis and potential clinical implications. J Biol Chem 2013;288(5):3500-3511. doi:10.1074/ jbc.M112.394510

[111] Tateishi K, Wakimoto H, Iafrate J, Tanaka S, Lobel F, Lelic N, et al. Extreme vulnerability of IDH1 mutant cancers to $\mathrm{NADH}^{+}$depletion. Cancer Cell 2015;28(6):773-784. doi:10.1016/j.ccell.2015.11.006.

[112] Galli U, Travelli C, Massarotti A, Fakhfouri G, Rahimian R, Tron GC, et al. Medicinal chemistry of nicotinamide phosphoribosyltransferase (NAMPT) inhibitors. J Med Chem 2013;56(16):6279-6296. doi:10.1021/jm4001049.

[113] Andronesi OC, Rapalino O, Gerstner E, Chi A, Batchelor TT, Cahill DP, et al. Detection of oncogenic IDH1 mutations using magnetic resonance spectroscopy of 2-hydroxyglutarate. J Clin Invest 2013;123(9):3659-3663. doi:10.1172/ JCI67229.

[114] Andronesi OC, Kim GS, Gerstner E, Batchelor T, Tzika AA, Fantin VR, et al. Detection of 2-hydroxyglutarate in IDH-mutated patients by in vivo editing and $2 \mathrm{D}$ correlation magnetic resonance spectroscopy. Sci Transl Med 2012:4:116ra4. doi:10.1126/scitranslmed.3002693.

[115] Choi C, Ganji SK, DeBernardinis RJ, Hatanpaa KJ, Rakheja D, Kovacs Z, et al. 2-hydroxyglutarate detection by magnetic resonance spectroscopy in IDHmutated patients with gliomas. Nat Med 2012;18(4):624-629. doi:10.1038/ nm.2682.

[116] Pope WB, Prins RM, Thomas MA, Nagarajan R, Yen KE, Bittinger MA, et al. Non-invasive detection of 2-hydroxyglutarate and other metabolites in IDH1 mutant glioma patients using magnetic resonance spectroscopy. J Neuro Oncol 2012;107(1):197-205. doi:10.1007/s11060-011-0737-8.

[117] Elkhaled A, Jalbert LE, Phillips JJ, Yoshihara HAI, Parvataneni R, Srinivasan $\mathrm{R}$, et al. Magnetic resonance of 2-hydroxyglutarate in IDH1-mutated low-grade gliomas. Sci Transl Med 2012;4:116ra5. doi:10.1126/scitranslmed.3002796.

[118] Kalinina J, Carroll A, Wang L, Yu Q, Mancheno DE, Wu S, et al. Detection of "oncometabolite" 2-hydroxyglutarate by magnetic resonance analysis as a biomarker of IDH1/2 mutations in glioma. J Mol Med 2012;90(10):1161-1171. doi:10.1007/s00109-012-0888-x.

[119] Ward PS, Cross JR, Lu C, Weigert O, Abel-Wahab O, Levine RL, et al. Identification of additional TDH mutations associated with oncometabolite R(-)-2-hydroxyglutarate production. Oncogene 2012;31(19):2491-2498. doi:10.1038/ onc.2011.416.

[120] Andronesi OC, Loebel F, Bogner W, Marjańska M, Vander Heiden MG, Iafrate AJ, et al. Treatment response assessment in IDH-mutant glioma patients by noninvasive 3D functional spectroscopic mapping of 2-hydroxyglutarate. Clin Cancer Res 2016;22(7):1632-1641. doi:10.1158/1078-0432.CCR-15-0656.

[121] De la Fuente MI, Young RJ, Rubel J, Rosemblum M, Tisnado J, Briggs S, et al. Integration of 2-hydroxyglutarate-proton magnetic resonance spectroscopy into clinical practice for disease monitoring in isocitrate dehydrogenasemutant glioma. Neuro Oncol 2016;18(2):283-290. doi:10.1093/neuonc/ nov307.

[122] Jafari-Khouzani K, Loebel F, Bogner W, Rapalino O, Gonzalez GR, Gerstner E, et al. Volumetric relationship between 2-hydroxyglutarate and FLAIR hyperintensity has potential implications for radiotherapy planning of mutant IDH glioma patients. Neuro Oncol 2016 Jul 5. doi:10.1093/neuonc/now100.

[123] Ganji SK, An Z, Tiwari V, McNeil S, Pinho MC, Pan E, et al. In vivo detection of 2-hydroxyglutarate in brain tumors by optimized point-resolved spectroscopy (PRESS) at 7T. Magn Reson Med 2016 Mar 16. doi:10.1002/mrm.26190.

[124] Elhammali A, Ippolito JE, Collins L, Crowley J, Marasa J, Piwnica-Worm D. A high-throughput fluorimetric assay for 2-hydroxyglutarate identifies Zaprinast as a glutaminase inhibitor. Cancer Discov 2014;4(7):828-839. doi:10.1158/2159-8290.CD-13-0572.

[125] Voelxen NF, Walenta S, Proescholdt M, Dettmer K, Pusch S, Mueller-Kliesler W. Quantitative imaging of D-2-hydroxyglutarate in selected histological tissue areas by a novel bioluminescence technique. Front Oncol 2016;6:46. doi:10.3389/fonc.2016.00046. 